\title{
Building a Student-Centred Learning Framework using Social Software in the Middle Years Classroom: An Action Research Study
}

\author{
Gail Casey \\ Deakin University, Geelong, Victoria, Australia
}

gcasey@deakin.edu.au

Executive Summary

This article discusses the development of the online spaces that were used to create a learning framework: a student-centred framework that combined face-to-face teaching with online social and participatory media. The author, as part of her Doctoral research study, used action research as a mechanism for continual improvement as she redesigned many curriculum projects for her thirteen Middle Years' classes, over an eighteen-month period. This article discusses part of this research study and specifically documents:

1. the complexity found within the tools and spaces of the selected social software, and

2. the continual review, through the action research cycle, in building the student-centred learning framework, and the consequent implications these had on the learning design.

The study uses a theoretical framework that values students as active participants in the learning process and sets up an environment where students can provide supportive feedback, and even assessment, to their peers. Through the open nature of social and participatory media, a peer-topeer modelling process was possible, where students could learn from the posts of others. In looking closely at the tools that enable peer-to-peer interactions to take place, this article highlights the challenges in utilising the dynamic nature of social media and the structural processes needed to support students in becoming active participants in their learning and the learning of their peers.

This article discusses the research study in three phases, and in each phase it provides two examples of teacher projects. In doing so, it presents screen clips of the online project as well as a structural diagram showing the analysis of the interaction within the project. The complexities and issues dealt with through the action research process are also highlighted. In describing this exploration, the article looks closely at the unique qualities that social software offers teaching and learning. It investigates many of the social tools such as 'My Page', Blogs, Groups and Discussion Forums. It also identifies the search tools and mechanisms that social sites offer in sup-

Material published as part of this publication, either on-line or in print, is copyrighted by the Informing Science Institute. Permission to make digital or paper copy of part or all of these works for personal or classroom use is granted without fee provided that the copies are not made or distributed for profit or commercial advantage AND that copies 1) bear this notice in full and 2) give the full citation on the first page. It is permissible to abstract these works so long as credit is given. To copy in all other cases or to republish or to post on a server or to redistribute to lists requires specific permission and payment of a fee. Contact Publisher@,InformingScience.org to request redistribution permission. porting the structural organisation of user-generated content in such a dynamic environment.

When considering the tools and mechanisms within social sites, it does appear that social media has the potential to alter how learners access information and knowledge, as well as how learners interact with the teacher and their peers. Through identifying and analysing the 
different social media spaces, the author was able to document the complexities involved in social sites and the range of options within the individual spaces. This highlighted the importance of the information retrieval mechanisms within such sites.

Through dissecting and analysing, the author became better informed as to the flow of student participation and interactivity within her class projects and was more able to construct a learning environment that provided students with individualised learning spaces. This was achieved through the use of blogs and each student's 'My Page'. Structurally, these were able to support personalised feedback from both peers and the teacher and were easily accessible for student assessment and the final reporting processes to parents. It was found that Groups and Discussion Forums were ideal for posting teacher project instructions and for student generated interest groups, as well as other interactions that were not likely to contain more than ten posts. It was clearly documented, within the research data, that when posting curriculum projects within potentially dynamic social sites, a high importance must be given to how the project will be structured and accessed. In this study, this helped to avoid students becoming lost (disorientated within the site), distracted or engulfed in confusion and information overload.

Keywords: online learning, social media, student-centred learning, learning design, complexity.

\section{Introduction}

As I walk down the street, pass the local shopping centre, and use public transport, I continue to be faced with people of all ages, using mobile devices. Markham (2013) explains that this instantaneous connectivity to personal networks and endless sources of information shapes every-day reality, and I am reminded of this as I check the 'Facebook' status of my two children, monitor my 'Twitter' account for resources from a recent educator conference, and respond to a 'connect' request from an academic on 'Linkedin' (see https://www.linkedin.com/). I live on a planet where the use of social and participatory media has become commonplace in the developed world, and increasingly so elsewhere. This has implications for my classes where many of my student's outof-school activities are focused around the social connectivity offered by computers and mobile devices.

This article reports on part of my doctoral action research study that investigated ways in which social and participatory media could be used to enhance the Middle-Years' (students aged 13 to 16 years) school curriculum. Three social media sites were created over an eighteen-month data collection period, and this article focuses its discussion on the structural design of these sites. It further discusses how this design evolved to build a student-centred learning framework. Specifically, it details:

1. The complexity found within the tools and spaces of the social software used.

2. The continual review, through the action research cycle, in building a student-centred learning environment, and consequent implications to the learning design.

\section{Technological Change and Social Software}

Put simply, social software encompasses all types of internet applications that support interaction between and within groups (Selwyn \& Grant, 2009). For the purposes of this article, social software, social media, and social networking are terms that can be interchanged. Current developments with technology and social software are significantly altering how learners access information and knowledge, as well as how learners dialogue with their instructors and with each other (Siemens, 2008). By virtue of their platform, social and participatory software provide the potential for creative and innovative learning. The articulation and understanding of the nature of the interactions among users, within social software and between the users and the tools that form 
part of the environment, are key challenges in researching new learning contexts through socially mediated environments (Conole, Gallery, \& Culver, 2011). This article looks closely at the tools that enable such interactions to take place and the challenges in using these to construct a framework that offers a student-centred learning environment. In explaining how this was done, it may be helpful to consider the ways in which social networks are unique.

In their special theme section on social networks, Boyd and Ellison (2007) survey research that is directly concerned with social network sites. In so doing, they set the scene for the scholarship and diversity that social software offers researchers. Their discussion on the history of social networking, dating back to 1997, provides a background to the shift in the organisation of online communities. What is unique in social networks, as explained by Boyd and Ellison (p. 211), is not that they allow individuals to meet strangers, but rather they enable users to articulate and make visible their social networks, and it is this that can result in connections between individuals that would not otherwise be made. Students of different ages and from the different subjects sharing the one social media site captured this uniqueness in this study.

Social and participatory media tools enable both open and closed interactions, and sharing of materials and information, to occur quickly from almost anywhere at anytime. Ryan, Magro, and Sharp (2011) explain that socialisation, whether educational or otherwise, leads to more inclusion, support, and understanding and this can help to alleviate the sense of isolation among students and can increase their chance of success. As the Internet and social media evolve, we are now discovering that knowledge can be produced, searched, organized, and shared in a seemingly infinite number of configurations, without necessarily resorting to an instructor or an external learning management system (Bouchard, 2011). This is emphasised in this study through the focus of a student-centred framework that is made possible by the World Wide Web (web). With the advent of such interactive web media, Bouchard asserts that for the first time we appreciate the act of learning as a response to changes in the learning environment, rather than as an adaption to a predetermined learning system. He argues that the traditional means of knowledge production, top-down and one-to-many, required in the past that the producer, disseminator, or publisher of knowledge distribute and organise information in a way that is intelligible to the learner. Bouchard discusses changes in the way learning occurs while Jones (2010), in his editorial on a new generation of learners, suggests a complex picture of change amongst young people, such that leisure and study activities intertwine. Jones asserts that new methods of research need to be adopted to complement the predominantly survey methods currently deployed. The lively interaction of online networks and relationships created through social media technologies is of growing importance to individuals, organizations, and communities, and understanding how these social media networks grow, change, fail, or succeed is of increasing concern to researchers and professionals (Hansen, Shneidermann, \& Smith, 2009).

As discussed by Jones (2010), the issue of technological change and the way it affects young people is important to networked eLearning because these include specific claims about approaches to learning in the new generation. This includes a change from teacher-centred to learning-centred based on collaboration and this change, in particular, supported this study, as the action research progressed, in building a student focused learning approach using action research. This included ongoing cycles of planning, acting, observing, and reflecting that became part of the teaching and learning process: hence, the growth, change, failure, or success of the interactions within the online social media site were continually being analysed. The action research cyclic process became complex as multiple classes were being studied at the same time and the action research cycle of one class informed the cycle of others. Complexity also existed within the social media tools, as found by Luckin et al. (2009) in their research relating to the activities and perceptions of learning with Web 2.0 technologies. Like Luckin et al., I found that the use of so- 
cial tools by learners can be categorised into four main groups (researchers, collaborators, producers, and publishers) and this could be seen in the many student responses to teacher projects.

In this article, I describe how the students used social tools and spaces. I dissect and analyse these to show the thinking and processes that occurred during the action research cycle, with the aim to optimise the peer-to-peer interactions (hence learning). Merchant (2011) acknowledges that researchers, over the years, have described the learning that takes place within such sites and he asserts that no model has yet been developed to theorise this learning. He argues that, despite claims that the social web is a rich space for informal learning, there has been little serious attention paid to the form or nature of that learning. Through this article, I hope that this research may contribute to the Model called for by Merchant by detailing possible structures within the learning process. Online networks easily trace the contours of existing social divisions as they transcend or transform (Merchant). The notions of 'social capital' and 'belonging' within social networking sites, as argued by Merchant, offer a context for more principled educational approaches to social networking. Merchant offers three approaches for the use of social networking sites in educational settings: learning about them, learning from them, and learning with them. Glimpses of these can be seen within the discussion provided in this article.

As more learning management systems within schools and universities are extended to include blogs, groups, chats, and discussion forums, the findings of research, such as this, will add to the important knowledge base for learning designers. This study highlights the complexities within social media tools and provides, within context, supportive examples and extensive explanations of how and why learning was structured. Its discussion, including varying constraints, may add to the growing bank of knowledge that supports the use of social and participatory media within educational spheres. While this article explains some of the pitfalls in using groups and discussion forums for teacher projects, it also aims to point towards solutions. The six examples of teacher online projects provide educators with samples of workable student-centred activities that were devised specifically for such dynamic environments. This study models the safe and secure use of social media within the teaching and learning sphere. It provides supportive evidence for those looking for examples of such use and also highlights a move from a teacher-centred approach to one that is learning-centred, within such social software.

\section{Theoretical Framework}

From the outset, this study involved the creation of a single social networking site shared between all of my classes during any one semester. Like Nuthall (2007), my experiences had led me to believe that teaching was about sensitivity and adaption, knowing that the things that interest some students do not interest others and what works one day may not work the next. The extensive research of Nuthall helped to provide this research with an appreciation of how different students experience the classroom, and how their experiences shape the changes that are going on in their minds. He argues that their motivations and interests, their attention and involvement may all be strongly affected by their ongoing relationships with their peers, and he asserts that teachers cannot be effective unless they take the peer relationships in the classroom into account. Although Nuthall does not discuss the concepts of social media in education, the importance he places on peer-to-peer interaction and influence were well supported through the social media environments used in this study.

There is without doubt a place for teacher instruction and individual work. Blatchford, Kutnick, Baines, and Galton (2003) suggest this and also that there is a need to construct a social pedagogy that can underpin the development of group work in schools. They predict that in the future, the distinction between teacher and pupil, or expert and novice, may well become blurred, especially as information becomes more widely and instantly available, a concept supported by this study. Blatchford et al. assert that learning is not just about information rather that the classroom of the 
future, and the pedagogy relevant, to it may be more about co-learners where students learn from and with each other.

This research study identifies a shift in the teacher to student relationship, through the integration of social media in the face-to-face classroom and in the concept of learning. These shifts, Davis and Sumara (2012) explain, help to move the cultural project of education to a new place, away from an ethos of segregated action and separated interests into a space of mutual challenge, joint interest, and collective production. These shifts are a result of the changes in educational technology that are concerned primarily with questions of what should happen and what could happen once new technologies and digital media are placed into educational settings (Selwyn, 2008). Despite their forward-looking, Selwyn asserts that educational technologists could be accused of having failed to keep abreast of the more critical analyses of technology that have come to the fore in other social science and humanities disciplines. He argues that the field of education technology should ask questions that could be termed 'state-of-the-actual' - that is, questions concerning what is actually taking place when technology meets the classroom. Rather than simply asking whether technology 'works' in education, Selwyn argues that educational technologists need also consider questions of how ICTs (re)produce social relations and what, if anything, can be said to be new about the social life of new technology. These 'state-of-the-actual' questions, Selwyn points out, necessitate taking as broad an approach to technology and education as possible in terms of methods, settings, and theoretical approaches. He goes on to explain that they also involve having as broad a mind as possible regarding the realities of ICT use and education. He points out that education technologists cannot afford to dismiss, out of hand, the alternative perspectives of other researchers from outside their field, and he asserts that we should be willing to concede that other perspectives on technology and education have some value and credence, despite the fact that they may not chime with our own experiences, opinions, or intellectual standpoints. Selwyn's perspective is important when considering this research because the study does not 'chime' with many of the more traditional approaches involving rows of student desks, school bells marking the beginning and end of each period, classroom order, and discipline; the approach taken in this study, through the integration of social and participatory media, could even be considered to contain many distractions to learning.

Modes of learning have changed dramatically over the past two decades and, as pointed out by Davidson and Goldberg (2009), our sources of information, the ways we exchange and interact with information, and how information informs and shapes our lives have also changed. As part of the Davidson and Goldberg research on digital media and learning for the MacArthur Foundation, they argue that the most important characteristic of the Internet is its capacity to allow for a worldwide community and its endless myriad subsets to exchange ideas and to learn from one another in a way not previously available. Their research examines potential new models of digital learning and it views participatory learning as a key term in thinking about emergent shifts. They explain that participatory learning includes the many ways that learners (of any age) use new technologies to participate in virtual communities where they share ideas, comment on one another's projects, and plan, design, implement, advance, or simply discuss their practices, goals, and ideas together. Participatory media begins from the premise that new technologies are changing how people of all ages learn, play, socialize, exercise judgment, and engage in civic life (Davidson \& Goldberg, 2009). My own study sought to build a student-centred learning environment that incorporated the participatory learning approach described by Davidson and Goldberg, where students had opportunities to become valued resources for others.

\section{Research Method}

This research is largely a qualitative study, although some numerical data was collected to help inform the action research cycle. I was both the classroom teacher and the researcher. I am a 
teacher of Mathematics and Information Technology and this research study involves students aged 13 to 16 years. I used action research throughout my classes and collected data over an eighteen-month period. The study took place in an Australian Year 7 to Year 12 co-educational public high school where I used Armstrong and Moore's (2004) elastic and permeable version of the action research cycle to progressively work through the process of designing and delivering a curriculum content that combined face-to-face teaching with social and participatory media. While focusing on students as active and valued participants in the learning process (Casey, 2011), the study explores the qualities that such media bring to the classroom. It also makes connections with chaos and complexity theories (Casey \& Evans, 2011).

Figure 1 provides a broader picture of the exploration of this research.

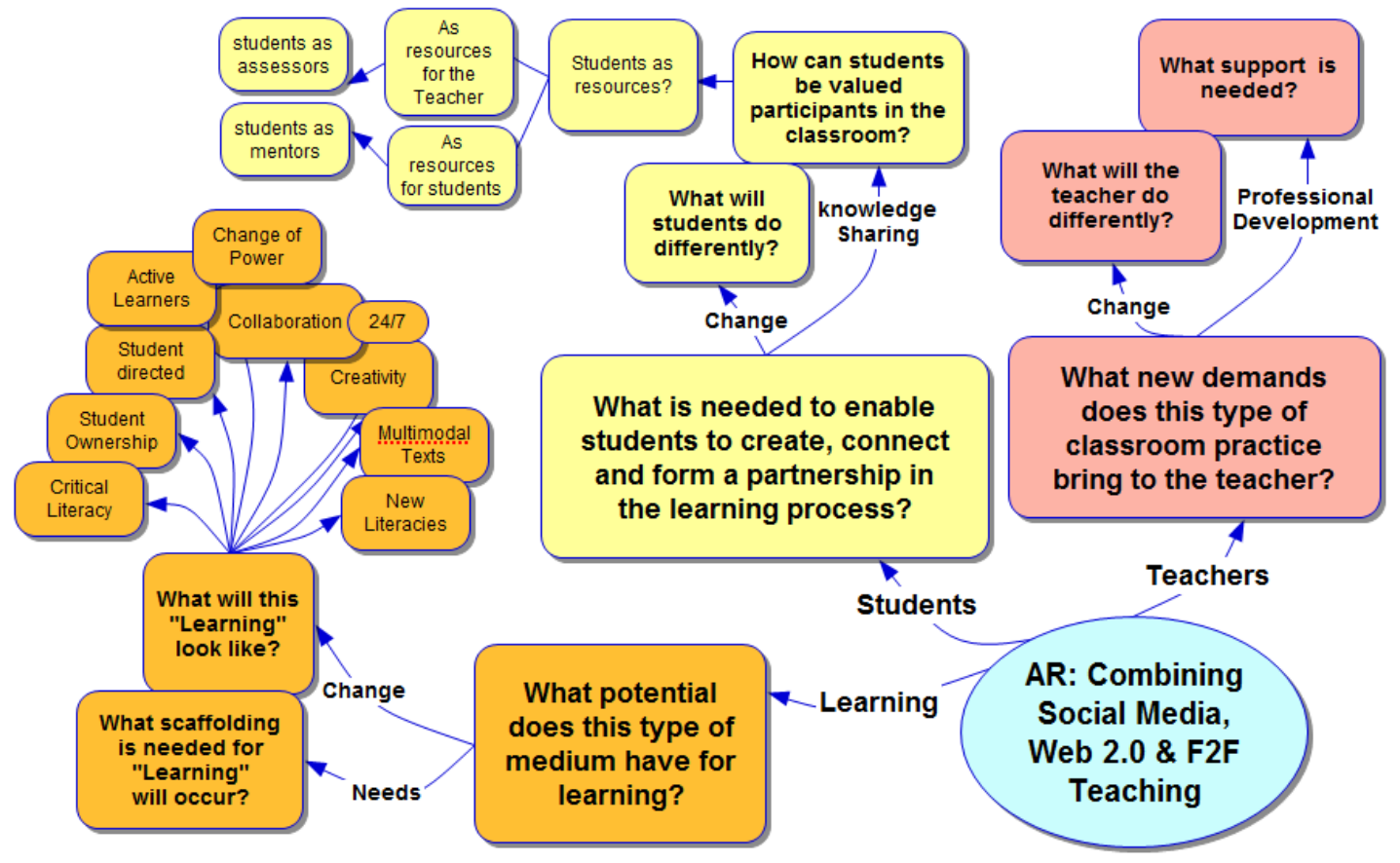

Figure 1: The research direction involves three foci: students, learning, and teachers.

Data collected included teacher planning documents, field notes, student work, end-of-week reflections, mid-term and end-of-term reflections, and critical friend feedback. Analysis was ongoing through the action research process where data was tagged and analysed in relation to the three foci areas shown in Figure 1: Students, Learning, and the Teacher. Each semester constituted one research phase and a new social network was created for each of the three phases and each was shared by all of my classes in the particular phase. Three social networking sites were used over the eighteen-month data collection period.

- Phase 1: Semester 2, 2010, http://ghs2010.ning.com/, involved the researcher's seven Middle Years' classes.

- Phase 2: Semester 1, 2011, http://ghs2011.ning.com/, involved the researcher's five Middle Years' classes.

- Phase 3: Semester 2, 2011, http://webtowhere.ning.com/, involved the researcher's one Middle Years' class.

I was the creator and administrator of the three social networking sites. I moderated all membership and the activity on each site. For privacy issues, students were encouraged to use pseudo- 
nyms (these added another dimension to the research) and students were not to post identifiable content. The site could be openly viewed on the Internet by anyone in the world, but only those with membership to the site could post content.

Although a social networking environment called a 'Ning', http://ca.ning.com/, was used throughout this research, the components of the Ning included blogs, discussion forums, groups and members pages, etc.; these are common on the Internet and in many learning management systems. Hence, readers may relate much of the following discussion to many other types of social software tools. It should be noted that the administrators of such environments, largely, have controls over the tools, facilities, and privacy of the site. The intention of this article is not to prescribe and delimit, but to offer readers some insight into the options when designing for learning using social and participatory media environments. One needs to keep in mind that the dynamic nature of such sites will continue to evolve.

\section{Learning and Interaction or Frustration and Information Overload?}

Initially when I posted my class materials on the social network, I found that some students had trouble navigating to the materials and others could become distracted by the range of links and content that surrounded them. At times, students became frustrated because they were required to click into pages that were linked within a series of other pages and, hence, there were many mouse clicks and screens to read. The development of an efficient and effective structure, for positioning content and for retrieval of information, soon became a key factor arising within the action research process.

The following Figures 2 to 11 provide information and screen clips showing many key features within the social network used in this study. The red arrows, embedded on many of the Figures identify key features and important quick access links to materials and content that was useful to the users (students) and visitors. These links can be accessed by a click of a mouse button and often provide further site content and links. The arrows point out a wide range of options that were available to students within the social media site. In creating the environment, it was important to consider and often incorporate these links into the online design framework for teaching and learning to avoid students becoming distracted or confused. As the research progressed, I found that it was imperative that I give careful consideration to the design of the main page, Figure 2, to optimise the flow of 'traffic'. The following pages provide a description of the different types of social spaces within the selected social site and they also highlight features that were considered when structuring project work and student interaction.

\section{The Social Network}

The Phase 2 main social networking page is shown in Figure 2. This main page was important because it provided a gateway to the site and the links to key social spaces. It was important to position project material within one or two mouse clicks of this main page and to highlight, to students, the 'Main Menu' as being an important means to navigate and to access significant areas within the site. This Menu (top left hand side of the Figure 2) appears in the same position throughout the site. The general search engine for the site, top right hand arrow, also appears on all site pages and was an important tool in helping to find a particular resource or member.

I could, as the site administrator, change aspects of the layout for the main home page and theme of the site at any time and, to some extent, I could determine the structure of the page and its subcomponents. Changing the layout would affect some of the points, indicated by the red arrows. For example, as the administrator, I could move the 'Groups' section shown on the left hand side 
of the main home page, Figure 2, to the centre of that page or even delete it from the page. This flexibility helped when designing the structure of the site.

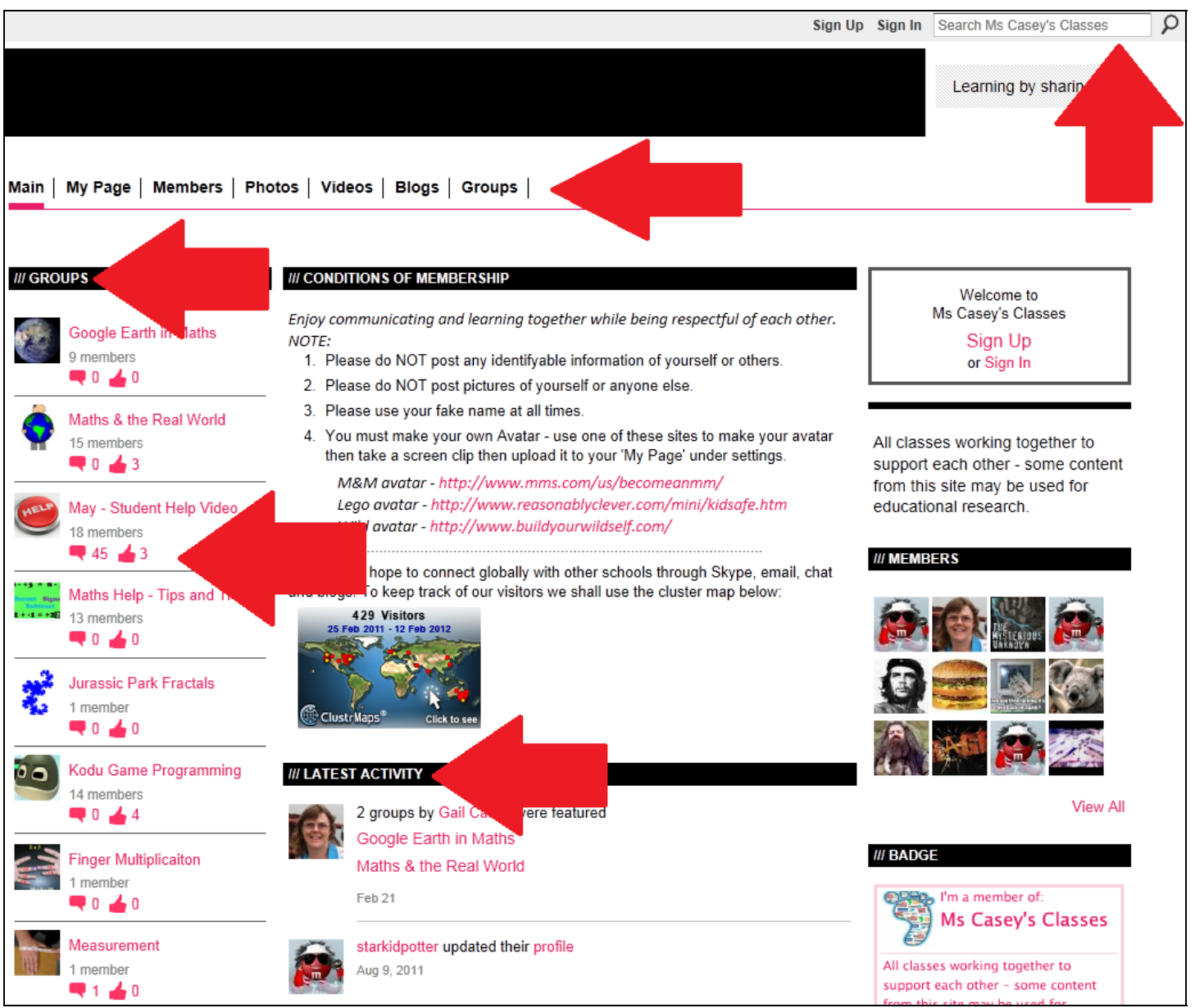

Figure 2: Quick access mechanisms available on the social networking main page (from Phase 2).

The other four arrows, in Figure 2, point to important quick access mechanisms for site users.

- 'Main Menu'. This provided convenient retrieval of the main site information that is categorised as Members, Photos, Videos, Blogs, and Groups. (The categories that appear in the Main Menu can be adjusted by the administrator.)

- 'Groups'. This is a filtered list, which the administrator set up, to enable 25 specific teacher created groups to be retrieved quickly. Without these quick links, students struggled to access the teacher set projects and content in a timely fashion.

- 'Comments' and 'Like' icons provided information on the total number of comments and 'likes' for each group. These allowed members and visitors access to information on the popularity and interactivity of the groups. They also provided users with a direct retrieval mechanism to the details of these comments and 'likes'.

- 'Latest Activity'. This provided members and visitors with detailed information regarding the most recent activity, updated as it occurred. The newest activity is shown at the top of this list. For the teacher, this information provided an essential mechanism for moderation. While in the classroom the teacher could easily view information on student 
activity while it was occurring. Outside the classroom it provided the teacher with a quick and easy information retrieval process to view student activity in more detail.

\section{'My Page'}

Social networks such as 'Facebook' (see https://www.facebook.com/) evolve around a page that is owned by each member, and this page links to their groups, blogs and their online friends' home pages, etc. It also provides a comment area where other members can leave messages, photos, and other embedded content. The Ning site used in this research was also centred on such a page for each member and this was called a 'My Page'. All members had their own 'My Page' and a small part of one of these is shown in Figure 3. This page was important in providing the member (the student) with quick links to their online friends, groups, blogs, and other content that they created. It also provided other students, and the teacher, with a central point where quick links to that member's content could be found. This page also provided the link where other members could post a 'friend' request' for the owner of the 'My Page'.

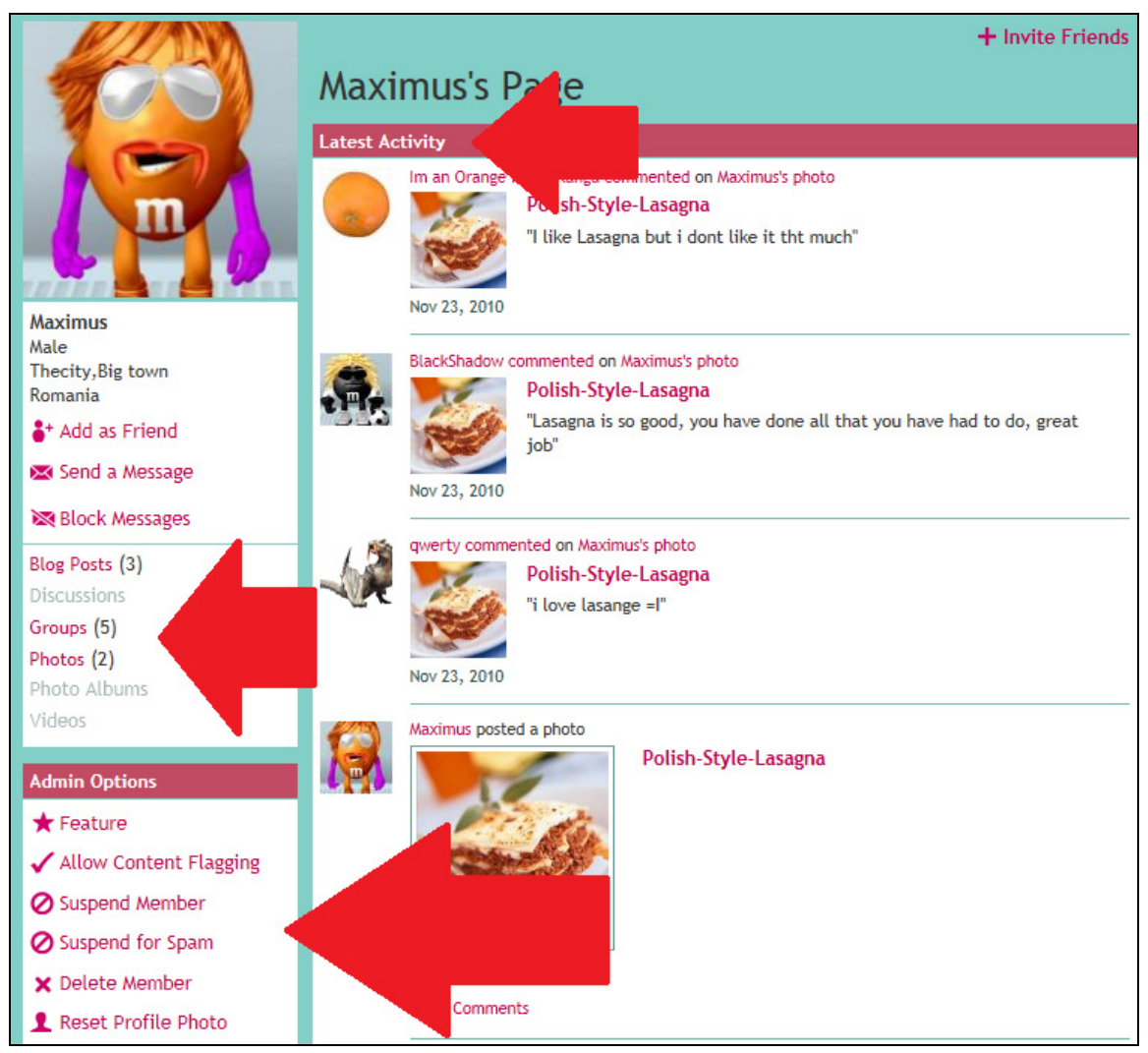

Figure 3: Quick access mechanisms from on a student's 'My Page'.

The three arrows, in Figure 3, indicate:

- 'Latest Activity' information for that member;

- links and information regarding the content created by that member: this has been categorised into 'Blogs', 'Discussions', 'Groups', 'Photos', 'Photo Albums' and 'Videos';

- and administrator options, only appearing when the administrator is logged in.

A more detailed summary of the information and the links that can be accessed from the 'My Page' is shown in Figure 4. 


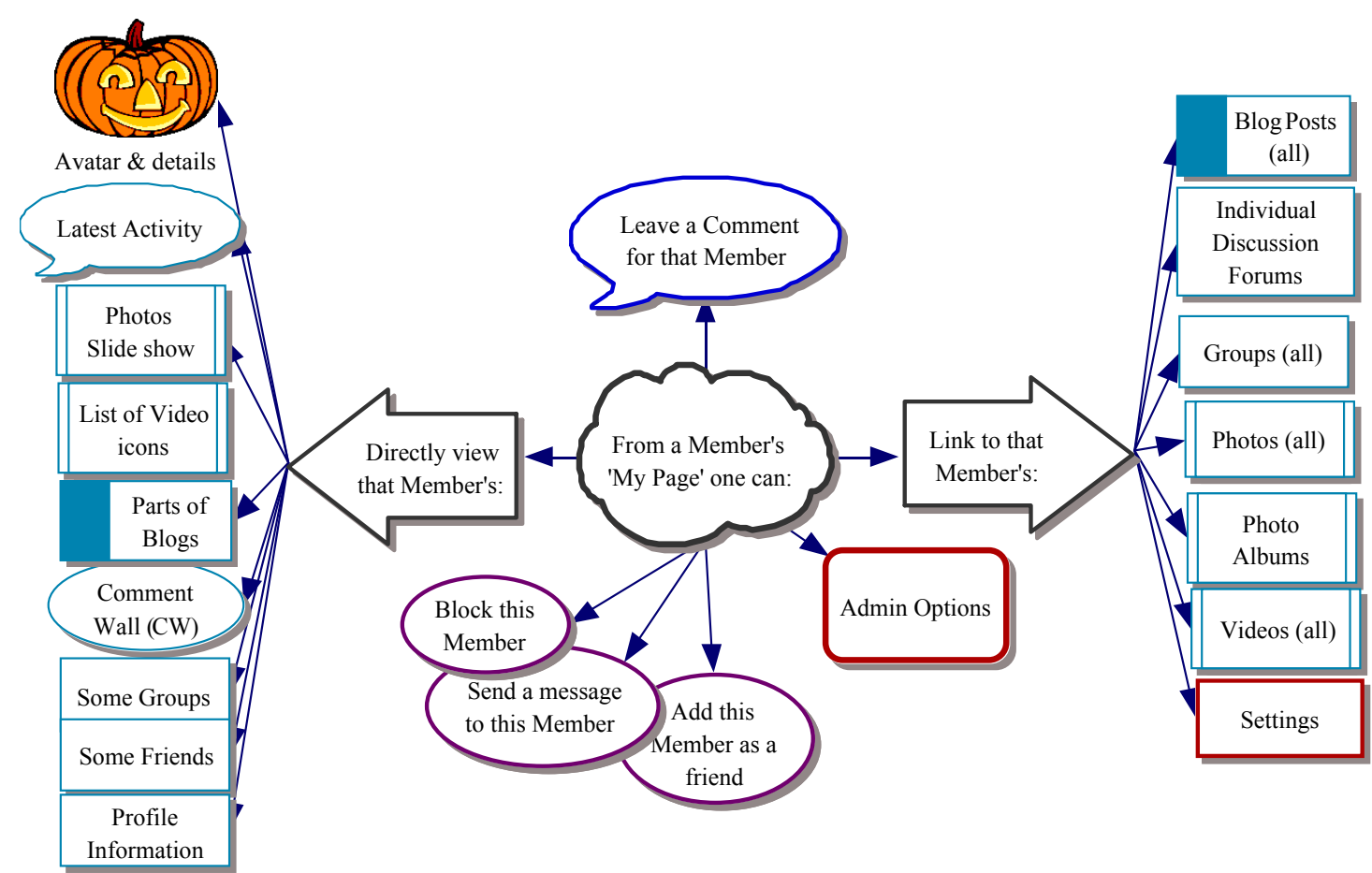

Figure 4: A summary of the possible information that could be accessed from a member's 'My Page' and further links to information that these provided.

The 'My Page', by default, showcased the activity of the individual member. As one scrolls down a 'My Page', information in the form of samples of specific content can be viewed. Access to the full content, through links, can also be obtained. From a student's 'My Page' it is possible to gain a snapshot of the avatar and online profile created by the student. It was by monitoring a student's 'My Page' that I could document the growth of what Merchant (2011) calls a student's 'social capital and belonging'. It is here that I could see the student-to-student connections made between classes and different subjects as well as within a class; much of this would not be possible in the face-to-face classroom.

\section{Blogs, Groups, and Discussion Forums}

Blogs, Groups, and Discussion Forums provided important online spaces for students to post their project work (text or user-generated content) and to interact with their peers by leaving and responding to comments. Clicking on the 'Blogs' link from the Main Menu can retrieve a list of all blogs, and information regarding each blog. The most newly created blog is listed at the top of the list. An example of this information is shown in Figure 5.

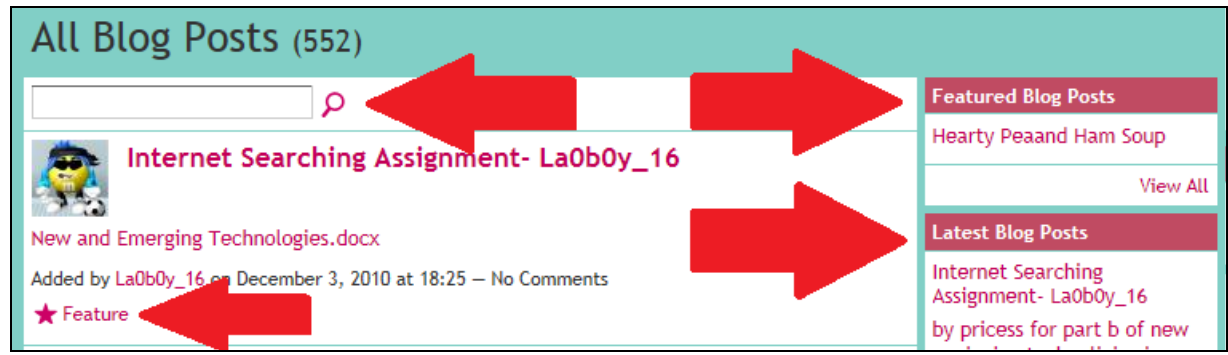

Figure 5: Quick access mechanisms on the 'All Blogs' page.

The four arrows on the 'All Blog Posts', Figure 5, are significant because these provide quick access mechanisms for students and the teacher to: 
- access the Blog search engine that provide users, both members and visitors, with the ability to search 'All Blogs'. This and other similar search engines ensure that the users are provided with options to retrieve information that meet their individual needs;

- use the 'Feature' icon that only appears when the administrator is logged in. This provides the administrator with a mechanism to filter the blog posts in a way that highlights selected blogs, hence, ensuring students can retrieve these highlighted blog posts from a prime position on the 'Blogs' page (at the top). The 'Feature' information retrieval mechanism can also be used for a range of other member uploaded or created content;

- have quick and easy retrieval of featured blogs (as just discussed);

- have quick and easy retrieval of other organised blog content such as the 'Latest Blog Posts', which then leads to the 'Most Popular Blog Posts', blog topics by 'Tags' and 'Monthly Archives'.

Analysis, through the action research cycle, showed that being aware of these quick access mechanisms and building them into the learning framework continued to be important when improving the designs of teacher projects; if students had difficulty in finding materials or peer content then less interaction would occur and the project would be less successful.

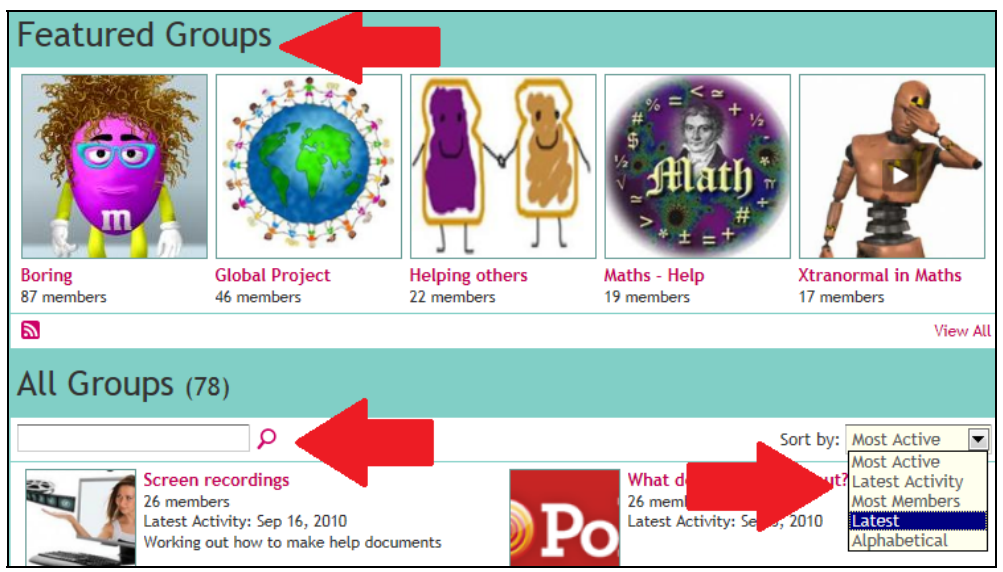

Figure 6: Quick access mechanisms on the 'All Groups' page.

All members could create Groups. The Main Menu was used to retrieve the 'All Groups' page as shown in Figure 6. The three arrows on this screen clip indicate:

- quick and easy retrieval of 'Featured Groups'. Note that these are always listed above 'All Groups';

- the Group search engine that provides the ability for members to search and retrieve information specifically within 'All Groups';

- 'Sort by'. This enables members to retrieve information on 'All Groups' by 'Most Active', 'Latest activity', 'Most Members', 'Latest' and 'Alphabetical'.

It is important to note that, within any group, options existed for members to create Discussion Forums. Discussion forums usually related to the theme of the particular group and contained links back to the group from which it was generated. Once a Discussion Forum was created, members of that Forum could leave any number of replies. As the number of replies in any one Discussion Forum increased, retrieval of specific replies became more difficult and students became lost in the quantity and complexity of how the information appeared. 
Unlike 'Discussion Forums', 'Forum Discussions' are discrete spaces of the Ning (not part of a group). Both are structured in a similar manner: however, a 'Forum Discussion' does not connect to, and was not associated with, another area of the social network, such as a group. I did not encourage the use of Forum Discussions, although occasionally I would create one to showcase specific content. Showcasing materials in this way meant that layers of other spaces or components of the Ning did not hide the content and, thus fewer mouse clicks were needed to access the information. Hence, retrieval of information from a Forum Discussion could be made directly from the main home page. The arrows in Figure 7 indicate the quick links available in both Forum Discussions and Discussion Forums.

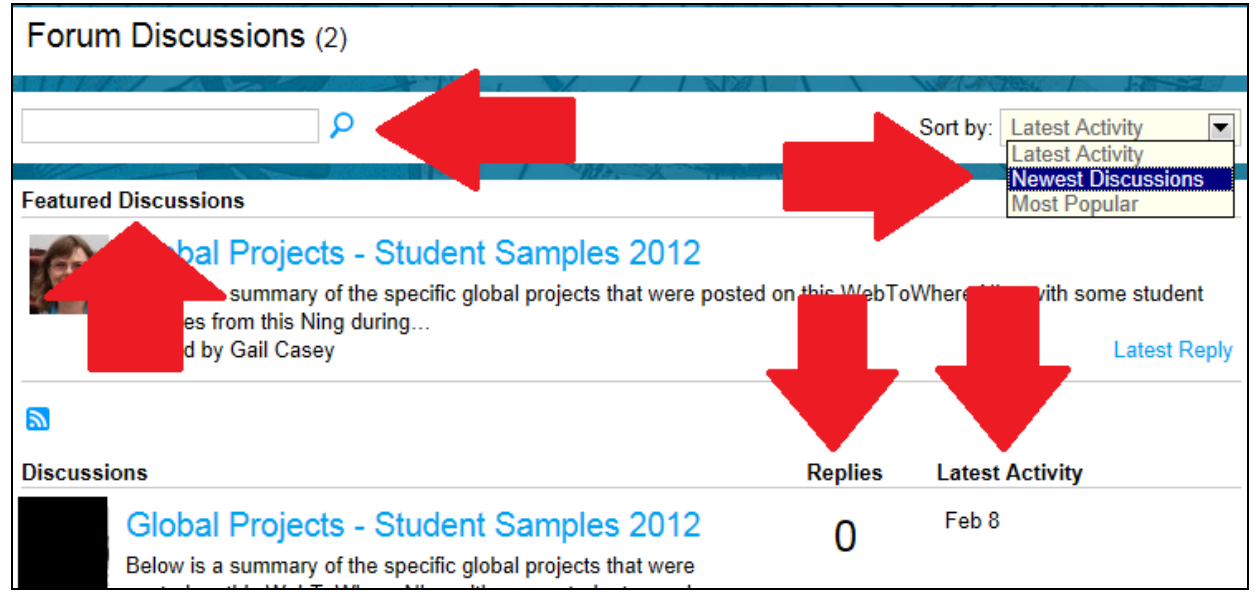

Figure 7: Quick access mechanisms on 'Forum Discussions' and 'Discussion Forums'.

Featured Discussions are always listed above 'Discussions'. The following provide explanations of the five arrows shown in Figure 7.

- The Discussion search engine provides the ability for members to search specifically within the 'Discussions' area.

- 'Sort by'. This enables members to retrieve the Discussions by 'Most Active', 'Latest activity', 'Most Members', 'Latest' and 'Alphabetical'.

- Quick retrieval is possible by accessing the Featured Discussions area.

- 'Replies' provides information on the number of replies occurring in any particular discussion. Accessing this information was extremely useful for both the teacher and the students. As the teacher, I used this information to encourage students to interact having those with a low number of replies and I also, as part of a peer-to-peer modelling process, directed students to those discussions with a high number of replies. For the students, they could retrieve important information on the activity of their discussion and they could, likewise, examine the discussions of others.

- 'Latest Activity' provided students with information that enabled them to recognise if a discussion was old or inactive. Retrieving this information helped students make decisions regarding where best to reply and where not to waste their time.

Note that there were no simple mechanisms to sort replies from a specific discussion forum or from a forum discussion. The oldest reply appeared on the top of the list of replies. This caused information retrieval problems when a large number of replies were posted.

I have been using Nings, Blogs, Groups, and Discussion Forums for many years and it was only through the analysis of the teacher projects and the student interaction that I gained further understanding of the complexity within the social media tools and, consequently, how important the 
quick access links were for student interactions to be successful. Projects were not successful if the number of interactions were so large that specific content was difficult to find. Projects were also not successful if there was limited interaction and, hence, shallow discussion.

\section{Members}

Knowing how to find and contact other members is an important part of the student interaction process within a social media site. A list of all members and a summary of their information could be retrieved from the 'Members' link on the Main Menu. The arrows in Figure 8 indicate the quick access mechanisms available from the 'All Members' page. This includes:

- quick and easy retrieval links to the featured members;

- the member search engine that provides the ability for members to search and retrieve information specifically within the 'Member' category;

- advanced search facilities that provide information retrieval mechanisms for searching the list of members, based on the profile questions as set up by the administrator;

- and 'Sort by' that enables the list of members to be retrieved by 'Recently Added', 'Alphabetical' and 'Random'.

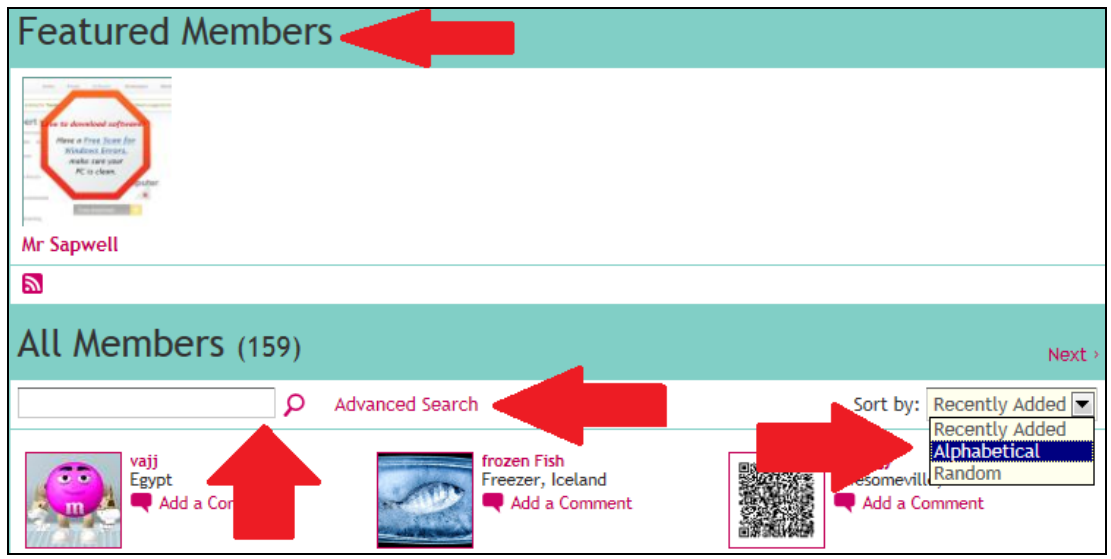

Figure 8: Quick access mechanisms on the 'All Members' page.

Information on any member of the social network could be obtained by clicking on a member's avatar. This would open the 'My Page' of that member where they could retrieve an extensive range of information about, and the user-generated content of, that member.

\section{Photos and Videos}

Photos and Videos were important in that they added opportunities for students to use, to create, and to share multimodal content. Students created and posted a range of video help tutorials during the study. They often took screen clips or photos of their work and published these as part of their assessment. All photos and videos on the site are available from the relevant link from the Main Menu. The 'All Videos' and the 'All Photos' pages, shown in Figure 9 and Figure 10, are very similar in design and function; they also offer the same information retrieval mechanisms.

The arrows on these screen clips indicate:

- the search engine that provides the ability to search specifically within the 'All Videos' or 'All Photos';

- and 'Sort by' that enables members to retrieve the list of photos or videos in order of 'Latest', 'Top Rated', 'Most Popular' and 'Random'. 
Note that, if photos or videos were 'Featured' they would appear at the top of the 'All Videos' or 'All Photos' page.

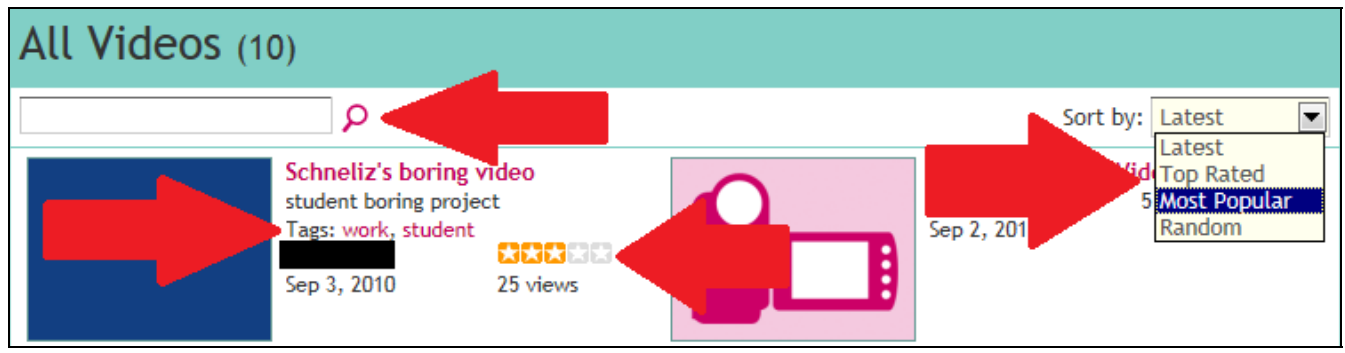

Figure 9: Quick access mechanisms on the 'All Videos' page.

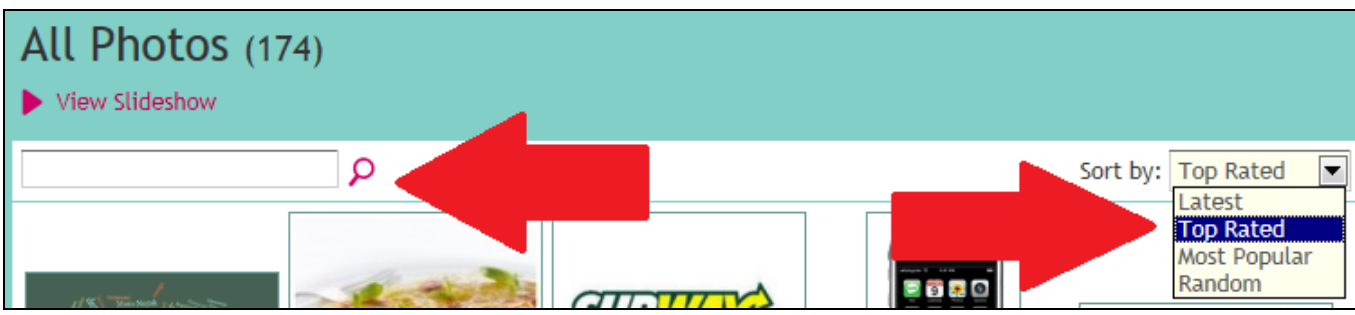

Figure 10: Quick access mechanisms on the 'All Photos' page.

Figure 11 shows one part of the screen when a specific photo or video is opened. The arrows indicate three important mechanisms available to help members categorise and judge content. Members can rate (on a five-point scale) all videos and photos as well as being able to mark these as 'Favourites'. When a member uploads or embeds a video and photo they have the option to add 'Tags' that help to categorise that piece of content. When the owner of the content adds a 'Tag' such as 'food' (as shown in Figure 11), members are able to type 'food' into the appropriate search engine and have all items with that Tag appear on the screen.

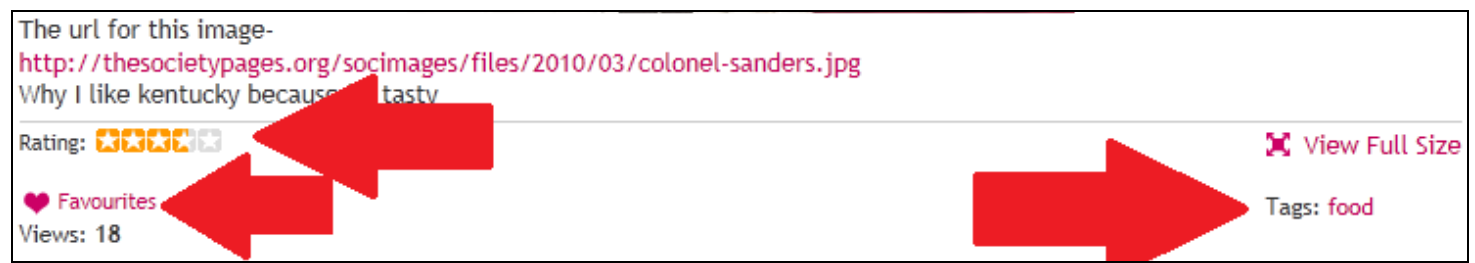

Figure 11: Mechanisms to help members categorise and judge content.

\section{Data Collection and the Analysis of the Social Software}

Data collected were categorised into the three themes: Students, Learning, and Teacher (as shown earlier in Figure 1). Each of these themes was broken down into categories, and tags were created for each category. These categories can be seen in Appendix 1. The data was organised using Microsoft OneNote software where folders and templates were set up. The student online activity during each phase was of prime importance in the analyses. Hence, for each class, individual student activity was summarised using a spreadsheet. Teacher planning documents, field notes and teacher reflections were also tagged and organised showing curricula links. Student work was tagged and summarised in themes. One example of this is shown in Appendix 2.

In the initial planning stages of the study, action research was chosen for its critical reflection and planning dynamics, as discussed by Armstrong and Moore (2004). As expected, the action research process was needed to continually improve and modify project designs and to find ways that encouraged active student participation. What was surprising, however, was the extent to 
which the action research process was needed to design a social networking framework that would ensure the projects could cope with the quantity of information generated (159 members over seven classes all shared the one social networking site during Phase 1). I did not wish to reduce the quantity of information generated but needed to continually reflect and review how the information was accessed and posted online. By necessity, information retrieval became an increasingly important focus in the learning framework that was beginning to develop.

Some of the changes in the learning design framework are described in the following pages. To fully appreciate the reasons behind these changes it is necessary to dissect and analyse the components of a 'Group' and a 'Blog'. It was this process that helped me to analyse student posts in response to teacher projects, enabling me to determine which structure was needed for a particular project and why. It was only working through the action research process, while constructing projects using groups and blogs, that enabled me to fully appreciate the implications of each component of a group and blog (even though I had been a solid user of such tools for many years).

I created groups on the social networking site to post project information, encourage student interaction, and provide a venue for students to publish, upload, and embed content. All groups, when created, by default, had four components (although some of these areas may not be viewable if they contained no content). These were:

1. A heading, including the Group information, tags and privacy settings;

2. The main Text box where the content could be added;

3. A series of Discussion Forums, if required, and

4. The Comment Wall where any member could leave a post.

The use of Blogs by students, on the social networking site, provided one solution when structuring learning activities to deal with large quantities of information. Blogs also provided students with a more individualised learning space; one that they could control.

\section{The Three Research Phases}

During the eighteen-months of data collection, the way that groups, discussion forums, and blogs were used was continually evaluated through the action research process. It was important to continue to improve how members might access peer content, how they could locate peers and interact with them, as well as how they might manipulate and analyse larger clusters of information. The discussion in the following pages provides specific examples of teacher projects within the three research phases. These highlight the evolving changes as the social networking site developed into a learning environment. I provide examples of two teacher projects within each phase and I do this by presenting a screen clip showing a picture of each project followed by a structured chart that shows some analysis of the interactions within that project. These examples are shown in Figures 12 through 23. In understanding the discussion surrounding these I note the following.

- The crosses shown over the 'Group Information' and the 'Text' boxes indicate that no interactivity can occur in these areas (they only display content posted by the creator of the group).

- 'Text' refers to the content appearing in the optional 'Text' box of the group. Although the site calls this a 'text box', other media can be embedded, attached, or linked within the text box. If the owner of the group does not place some text into this area then the 'Text' box does not appear on the group page. 
- Any number of discussion forums may be created in a group and each discussion forum has the facility for members to post replies to that specific discussion. Any number of replies may be posted to a particular discussion. Similarly any number of comments may be posted on a group's comment wall and these are usually comments specific to that group (not a particular discussion forum within that group).

- The cross that is shown over the 'Replies' box indicates that, although members may post to this area, the messages, here, are expected to be responses only to the specific content initially posted by the owner of the Discussion Forum. Confusion is caused when replies are made to previous replies. The ability to have one-to-one replies is very limited and it was found that as the quantity of replies increased, the interactivity of discussion became difficult for members to manage and understand. (This is because all replies are in date stamp order, as is the case with most site activity.) The cross over the 'Comments on CW' box similarly indicates that comments are not expected to be made in response to earlier comments.

\section{Phase 1 of the Action Research Cycle - Semester 2, 2010}

In the following two examples, from Phase 1, I highlight the complexities in using 'Groups' to post project work and the difficulties found when retrieving content and following student interactions as the level of online activity increased. The examples also point out the problems, when content was difficult to find, in finalising assessment at the end of the semester.

In Phase 1, I often created an online group to post my teacher project instructions. Students initially retrieved these from a discussion forum that I had created within the particular group. I would then 'Feature' this discussion forum to ensure that it appeared at the top of the discussion list. However, students struggled with this for various reasons including the excessive number of mouse clicks, from the main home page, required to retrieve the information. As the first phase progressed, I modified this process, using the action research cycle, by analysing and altering different organisational structures. I found that project instructions were more quickly retrieved by students if I posted them in a group text box, rather than a discussion forum within a group. Project instructions remained more visible, to students, when I placed the instructions in a group text box. This also required one less mouse click from the main page.

\section{Phase 1 - Example 1}

Figure 12 shows a screen clip of one of the early Phase 1 teacher project groups; the project was called 'I can't believe my eyes'. This example shows that once the number of discussion forum replies or comments flowed beyond one page (10 items can usually fit on one page) the information retrieval processes for students became more difficult and I needed to spend more time helping students find the information and to stay on task.

The heading in the text box is 'Week 4 - Instructions'. A breakdown of the components for this group is shown in the structured diagram in Figure 13. This structured diagram provides the number of comments on the comment wall, of the group, and the number of discussion forums as well as the total number of replies on each page of the discussion forum. (Note that this group contained two pages of discussion forums.) 


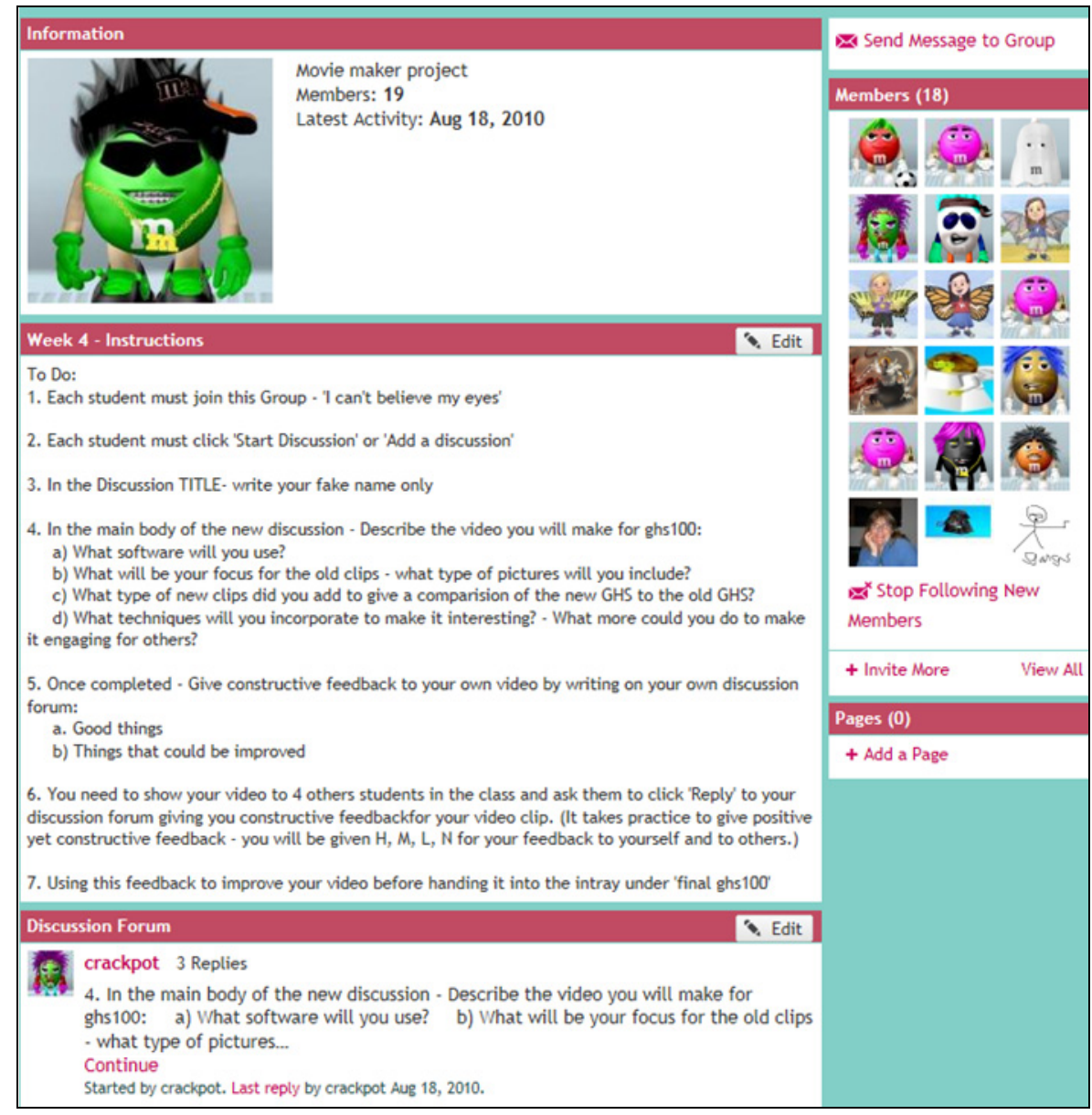

Figure 12: A Phase 1 group created by the teacher. This was for the 'I can't believe my eyes' project.

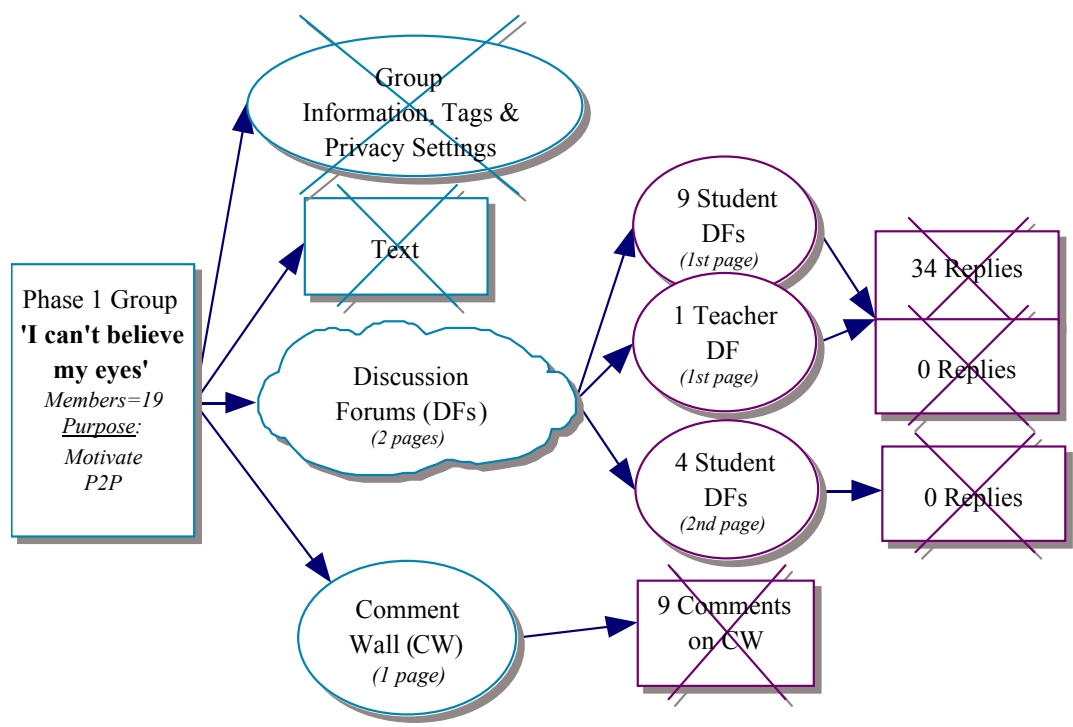

Figure 13: A structured diagram showing the breakdown for the group displayed in Figure 12. 


\section{Phase 1- Example 2}

The most complex class project during Phase 1 was called the 'Boring' project. A screen clip of this group is shown in Figure 14; it involved a total of 87 members. The project requirements resulted in a large number of members interacting and this became chaotic and very difficult to follow individual students. The structural chart, Figure 15, shows the large number of replies within different discussion forums, within the group. This project was significant in highlighting the need for me to do things differently. These are summarised in the four points at the end of the example. This group included three structural components:

1. a text box, displaying 'Have you chosen your boring object? Next.....';

2. a teacher created discussion forum to encourage students to think more about the concepts of 'Boring' and 'Interesting';

3. and a teacher created discussion forum where students described one thing they found boring (without telling others what, exactly, it was that they found boring).

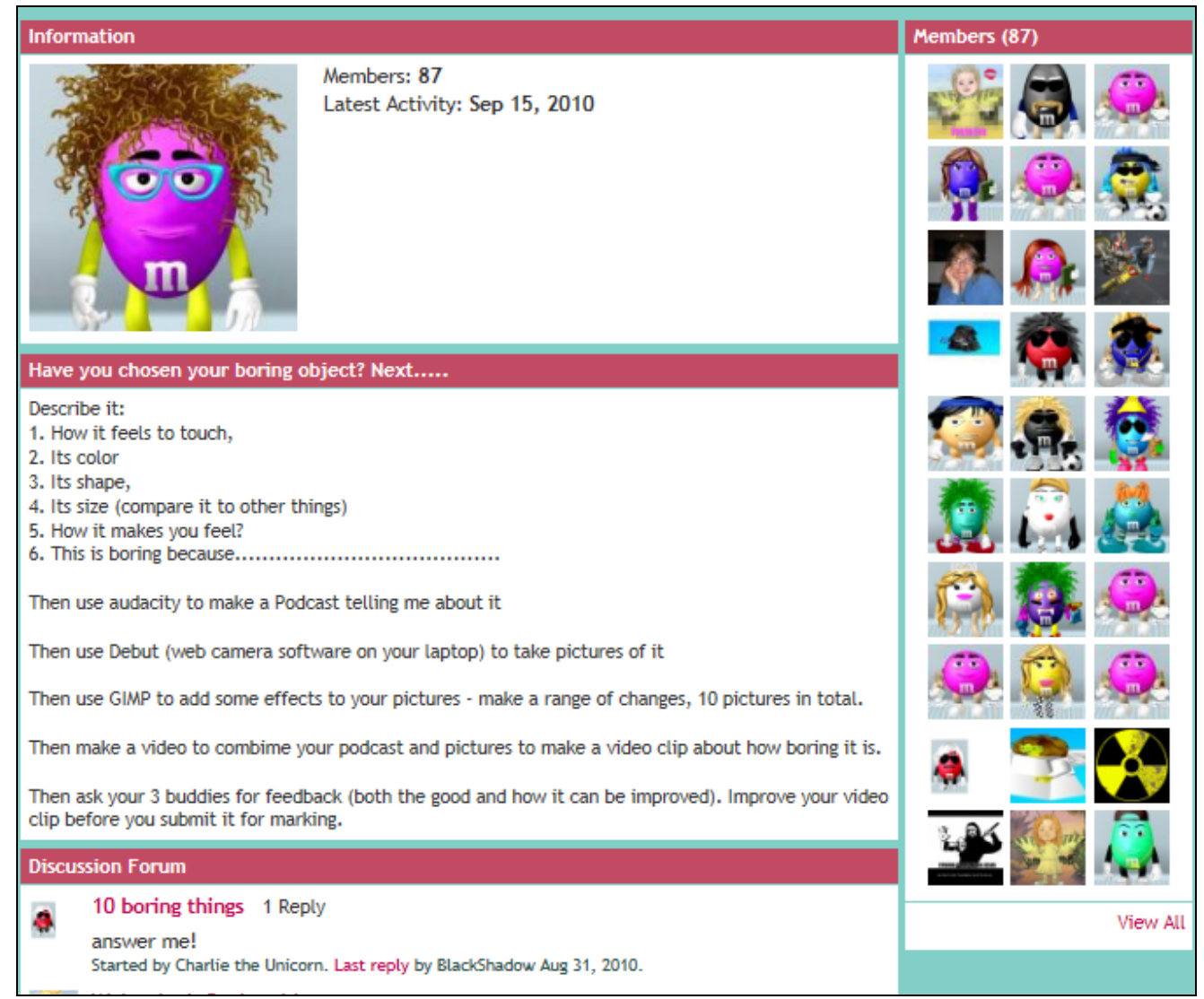

Figure 14: The most complex Phase 1 group created by the teacher. This was for the 'Boring' project. 


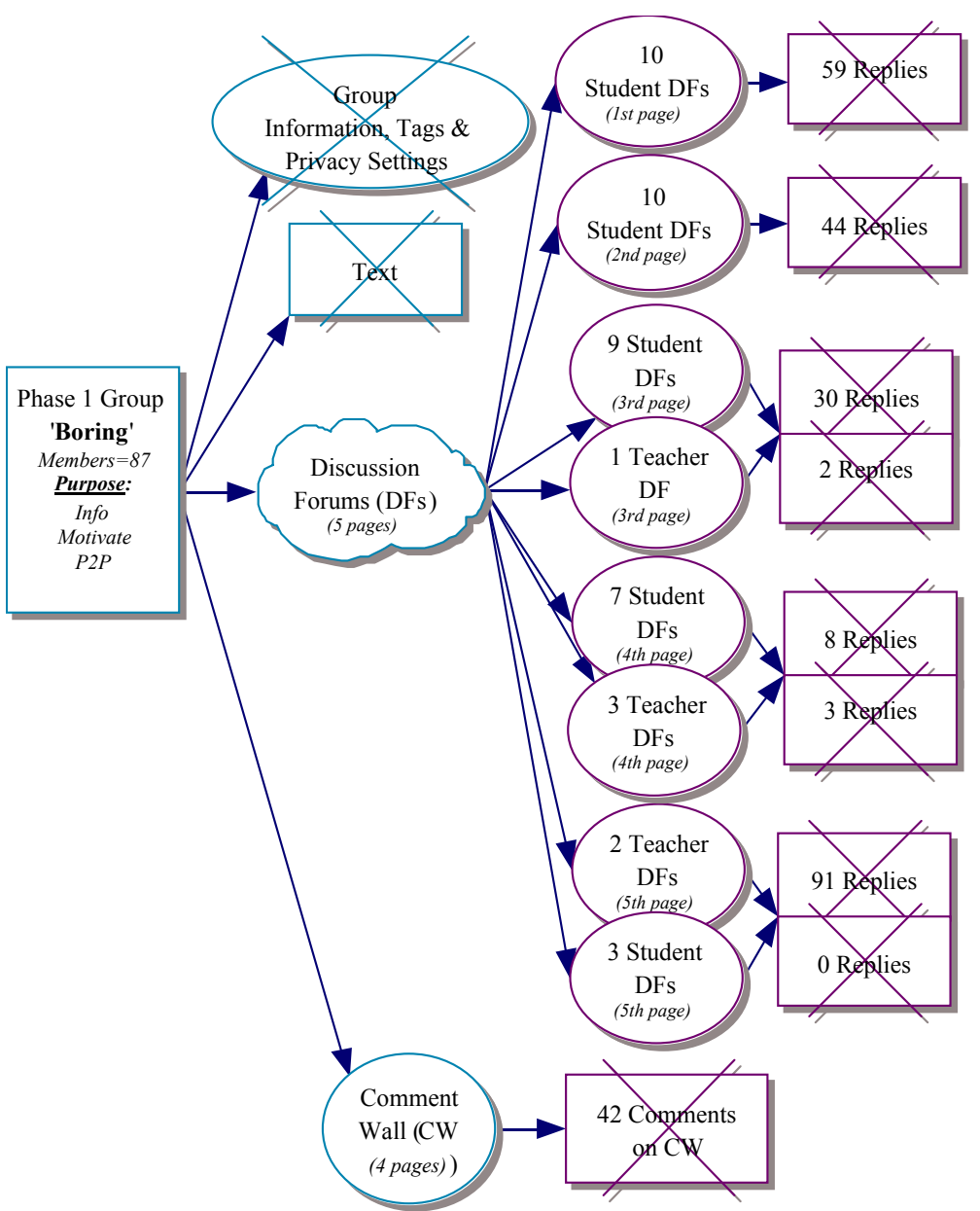

Figure 15: A structured diagram showing the breakdown for the group displayed in Figure 14.

Through the action research process, and a broader analysis of the many teacher directed projects developed during Phase 1, the following findings were used as foci during Phase 2.

1. There is a need for the project instructions to be retrieved from the text box of a group.

2. Additional Groups for the project should be created if the number of comments posted on the Comment Wall grows to more than one page. (At times there were three pages of comments resulting in information being hard to retrieve.)

3. At times students would respond to posts on the comment wall or replies in discussion forums by responding to the individual member on their 'My Page' (this was easily done by clicking on their name or avatar). But, this was not ideal for the teacher because it took some of the project interaction away from the project group and that interaction was then harder for peers to follow.

4. Throughout Phase 1, I often viewed each of the student's 'My Page' and could see the wide range of activities and interactions in which a particular student was involved. (This was largely done from the student's list of 'Latest Activity'.) However, at the end of the semester, it was difficult to see the full extent of this activity because the student's work was scattered over too many groups and could not easily be found. Although the 'My Page' lists the groups in which that student is a member, information as to whether the 
student actively contributed to that group was not available without actually going into the particular group page. This was a concern when wanting to finalise assessment.

\section{Phase 2 of the Action Research Cycle - Semester 1, 2011}

As Phase 2 progressed, I began to realise that the decisions I was making within the action research cycle were growing in complexity, and the significant quantity of student interaction occurring within project work was also providing complex pictures of interaction and learning. I began to make connections with the work of Brent Davis and Dennis Sumara (2006) published in their book 'Complexity and Education'. I gained confidence from the work of Sumara and Davis (2009) as well as Hayles $(1990,1991)$ and Doll $(2005,2012)$. The Chaos and Complexity within this study is discussed further and documented in Casey and Evans (2011). During Phase 2, it became clear that the way in which knowledge was being provided and structured on the online social site was achieving a more student-centred environment than in my previous teaching experience. An increasing number of students were interacting and sharing their ideas. From this sharing, the data showed that students were able to be the providers of some types of knowledge for their peers. The words of Ravenscroft and Cook provide a central pedagogical idea that supports the type of learning that I valued through this student interaction, “...students should learn to think and to think together" (Ravenscroft \& Cook, 2007). I called this approach "knowledgebuilding' and connections to this type of pedagogy, for this study, are discussed further in Casey (2011).

Data from Phase 2 highlights the development of a knowledge-building priority within the action research process. During this phase students were not always asked to join the teacher project groups and were often encouraged to view the project instructions without joining the group and, hence, often did not post comments or interact on the group page. As will be explained in the examples, this helped to relieve the congestion of student interaction in discussion forums and groups.

\section{Phase 2 - Example 1}

One teacher project group, within Phase 2, was called 'Data Visualisation', shown in Figure 16. This group was created to encourage students to connect mathematics with real world concepts such as earthquakes and floods. Membership to the group was optional and I note that the group only had three members. This was because students could engage with the activity by using the websites and information provided on the group, but they were not required to post comments or content with the group online page. The absence of interaction within the group page can be seen in the structured chart of the group, shown in Figure 17. 


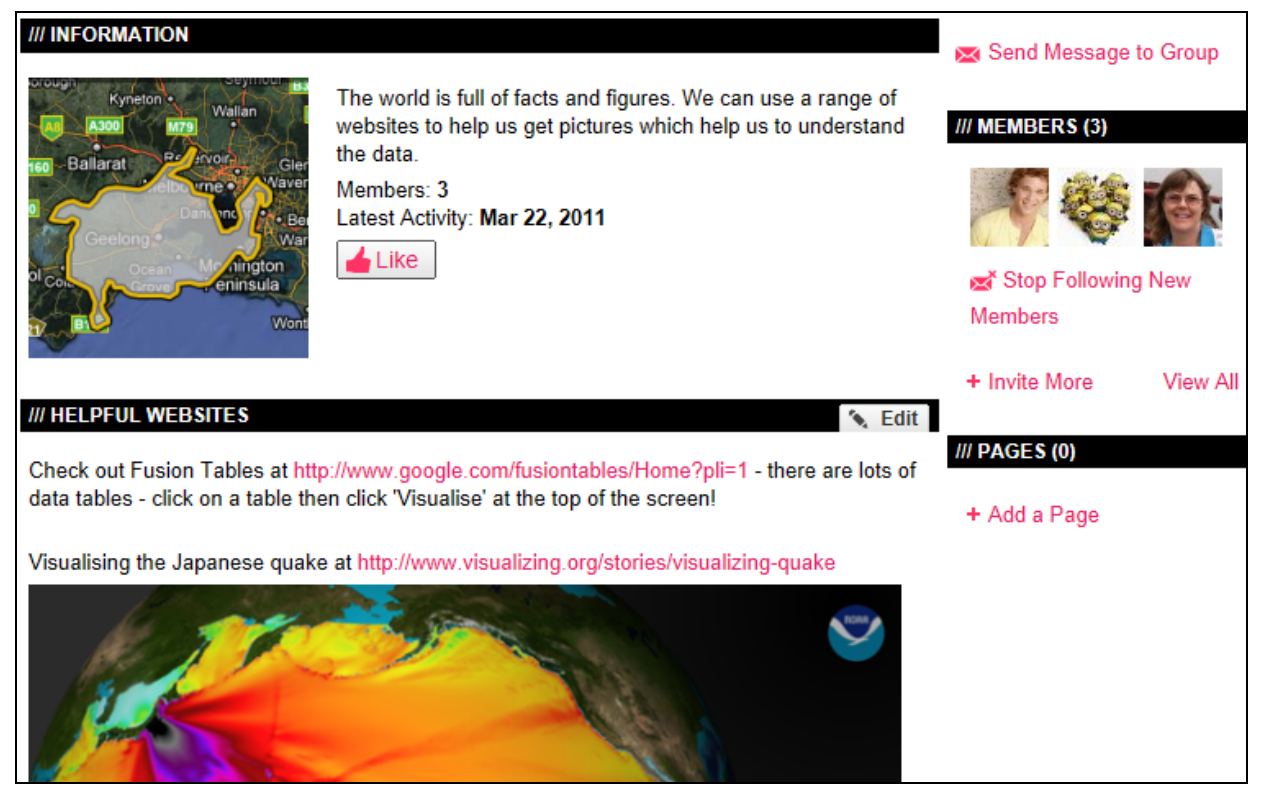

Figure 16: A Phase 2 group created by the teacher called 'Data Visualisation'.

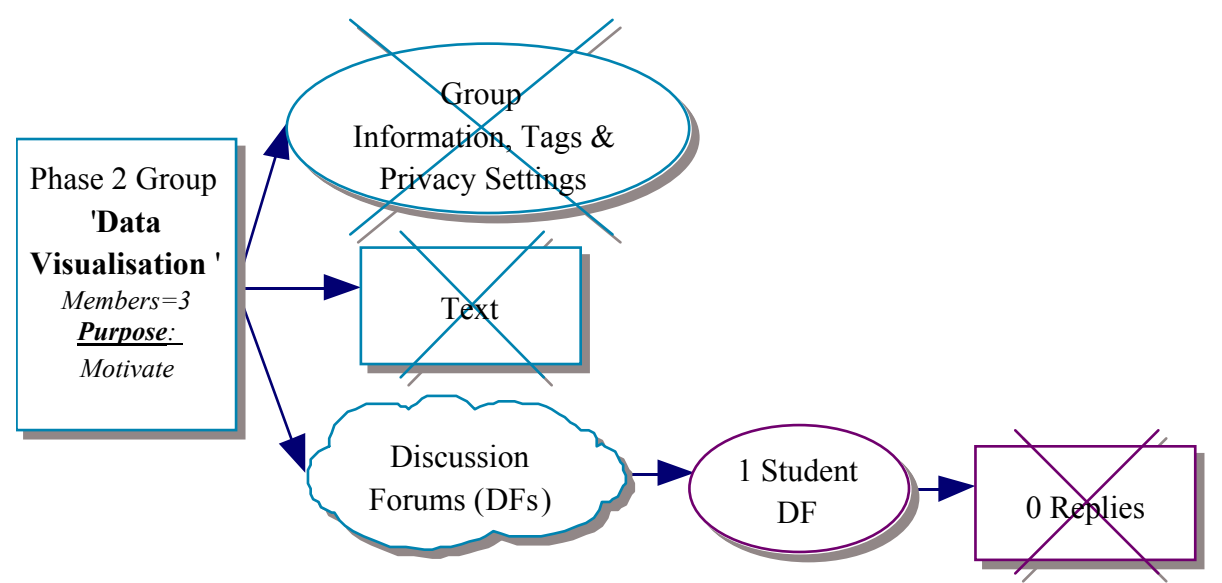

Figure 17: A structured diagram showing the breakdown for the group displayed in Figure 16.

Within this project, students could easily access and engage with the content. However, I was disappointed that student discussions occurred only in the face-to-face classroom, and not online. This meant that only students within one class were sharing their thoughts and ideas. I was hoping that students would choose to post their conversations online, without my encouragement, so that students across subjects and age groups could interact; hence, the discussions could be 'richer' and the concept of 'knowledge-building' could further develop.

\section{Phase 2 - Example 2}

In Phase 2 I extended the project shown in Example 1 by asking the students to create their own blog and then to use this blog to post and discuss their work. This example comes from a project called 'Kodu Game Programming'; the project group is shown in Figure 18. Students retrieved the project information from the group text box and because the project contained detailed explanations, I also created two discussion forums within this group to post instructions. These were used to help break up the teacher instructions into smaller parts. 


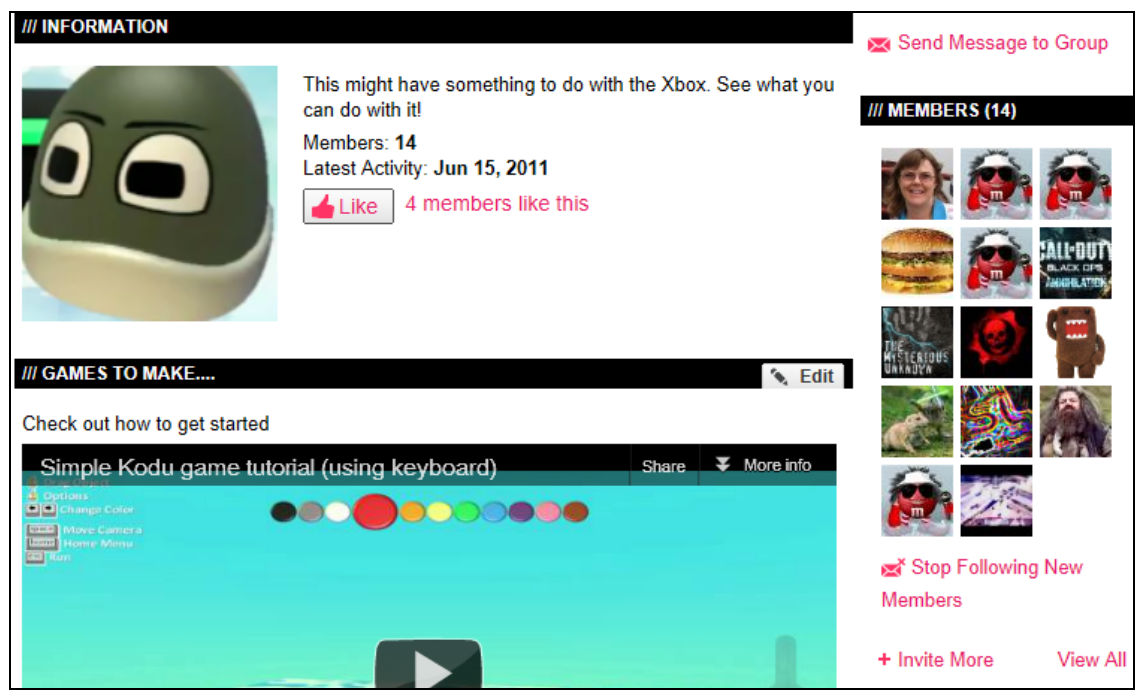

Figure 18: A Phase 2 group created by the teacher. This was for the 'Kodu Game Programming' project.

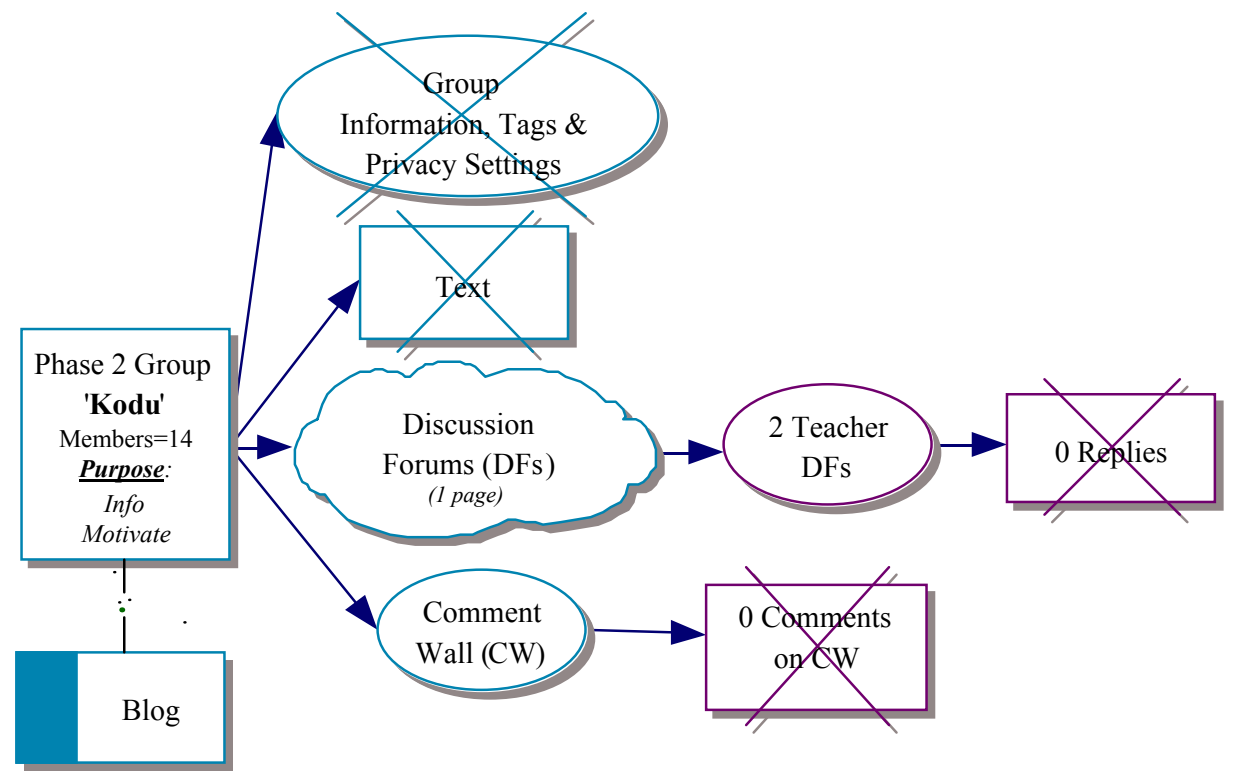

Figure 19: A structured diagram showing the breakdown for the group displayed in Figure 18.

As can be seen in the more detailed structured diagram for this group, Figure 19, there was, again, no interactivity within this group. However, I note that in one of the teacher discussion forums the students were instructed to create a blog where they were expected to describe their work, upload their user-generated content, and gain feedback from their peers. This approach was very successful and encouraged more individual peer-to-peer interaction; this generally occurred online but some students did this in the face-to-face classroom. As part of this peer-to-peer interaction, students had three peer mentors who were asked to provide constructive feedback on the student's work, and these mentors were eventually expected to give peer assessment. How students obtained their three peer mentors was initially a challenge because I did not want to allocate peer mentors, and I had concerns with students choosing their own. Also embedded within the study was the added issue of students using pseudonyms online. (Students could change their name as 
they so desired and without warning and were encouraged not to give out their online pseudonym in the face-to-face classroom.) To find out who their peer mentors were, students used the 'Blogs' link from the Main Menu to find their own blog, within the list of all Blogs. Then they found two of their three mentors by using the owners of the blog immediately above and below their blog in this list. Students had free choice of their third mentor and could find them quickly and easily.

\section{Phase 3 of the Action Research Cycle - Semester 2, 2011}

Phase 3 used the experiences I had gained from the data analysis of Phase 1 and 2. I had, at this point, implemented a range of projects using groups to post instructions and blogs to develop personalised constructive feedback. I had gained the confidence to move the study one step further by opening up and sharing the social learning network with schools outside Australia; from Russia and Romania. During this final phase I taught only one face-to-face class, in Australia. After considering issues such as physical distance and varying time zones, I designed and set up support mechanisms to help students and teachers. I did this in a group called 'Getting Started' where I posted a range of resources and instructions.

\section{Phase 3 - Example 1}

This project was not designed to encourage students to interact; it was a type of 'warm up' activity to encourage students to explore a range of Web 2.0 tools in the hope that they would use these for project work later in the semester. This project was designed to help students explore

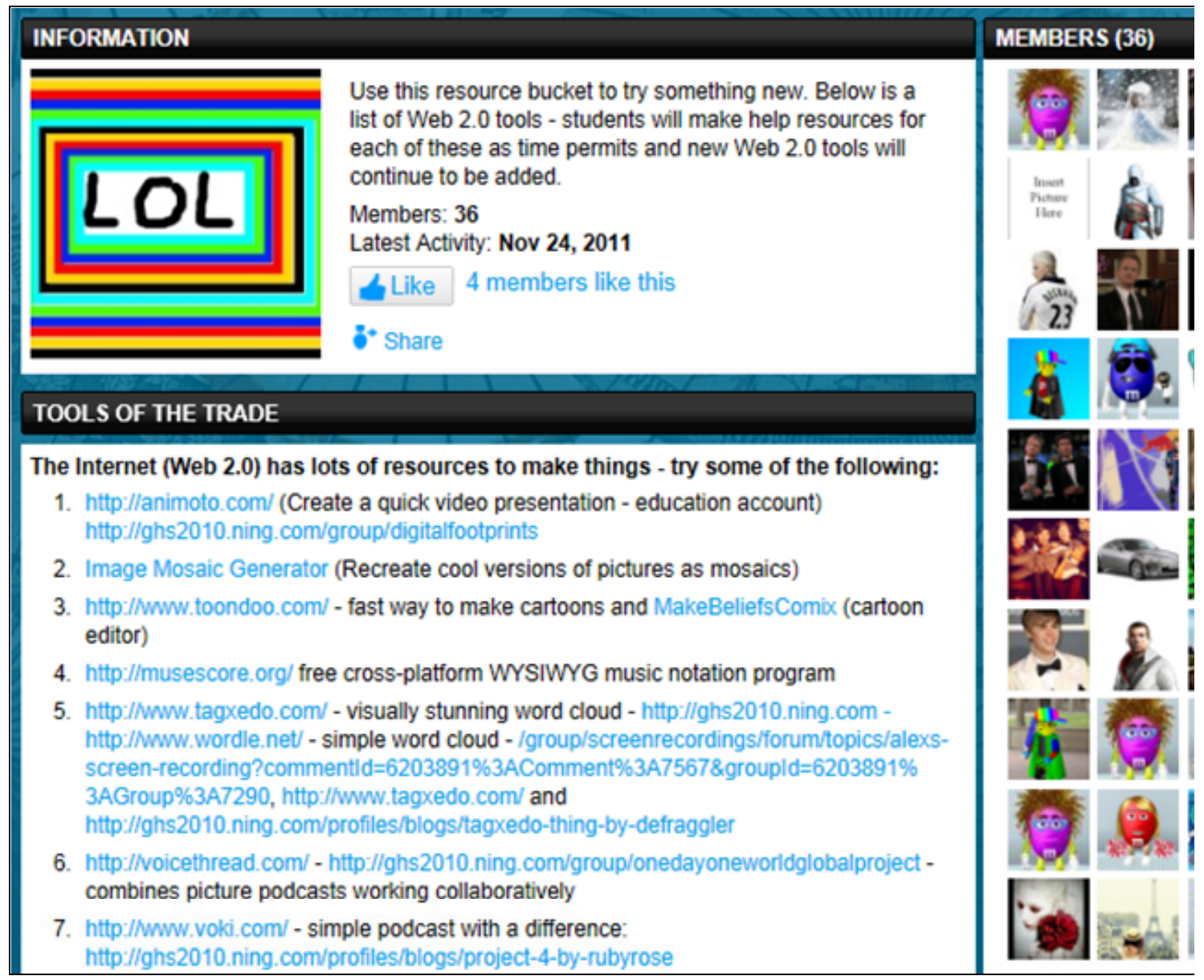

Figure 20: A Phase 3 group developed by the teacher called 'Get Creative'. 
different ways of presenting their ideas and work content. The project was called 'Get Creative' and provided students with a choice of up to twenty-one Web 2.0 tools; a screen clip showing some of these is shown in Figure 20. The purpose of this group was not for students to give each other feedback. This group provided students with a space where they could practice publishing, linking and embedding Web 2.0 tools in the comment wall for the group. However, I found that students wanted to comment on the work of their peers. The work of their peers engaged them and students found the structure of the project frustrating because the work of their peers was difficult to find and their comments became lost in the multiple pages of comments. Students wanted to see how their peers had used these Web 2.0 tools and in many ways students, through the open publishing nature of social media, became models for their peers.

As can be seen in the structural diagram for this group, Figure 21, students posted a total of fiftyseven posts on the comment wall in this 'Get Creative' group. Consequently, data retrieval became increasingly difficult once the comments flowed over one page (10 posts). I planned this activity as a type of 'play time' for students and did not intend that students would interaction or provide feedback. I was wrong to not design the project for interaction. In the face-to-face classroom, students indicated that they wanted to communicate and interact, but the structure of the project did not allow for this. In hindsight, I should have designed the interaction within the activity with a combination of blogs and discussion forums or, perhaps, one discussion forum for each of the Web 2.0 tools rather than only the comment section of a group.

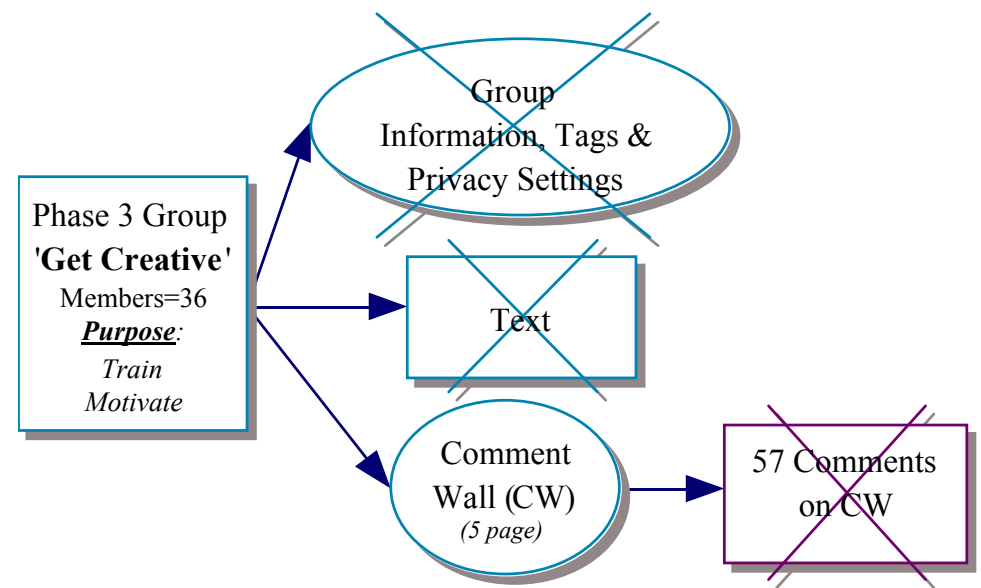

Figure 21: A structured diagram showing the breakdown for the group displayed in Figure 20.

\section{Phase 3 - Example 2}

This final example was the last project in the eighteen-month study and provides insight into the main student-centred framework that evolved during the study. This example was created in a group called 'Global Classroom' and was part of a much larger and complex project. A second group called 'StudentGroups' was created to help break up the student generated content and break the student interactions into manageable clusters as the quantity of data grew. By using a discussion forum in the 'StudentGroups' I asked the students to create a blog where they could inform others about their topic and where they could post relevant pictures and other content. This also helped to alleviate issues of information flow when searching for student content and interaction. Directing students to use blogs opened up the opportunities for peer-to-peer feedback that was more individually focused, and it helped to personalise the student's learning. In hind site, the use of three distinct groups leading to blogs, rather than only two would have further improved access to the peer interactions. The structural diagrams for each of the two groups used in this 'Global Classroom' project are given in Figure 22 and Figure 23. 


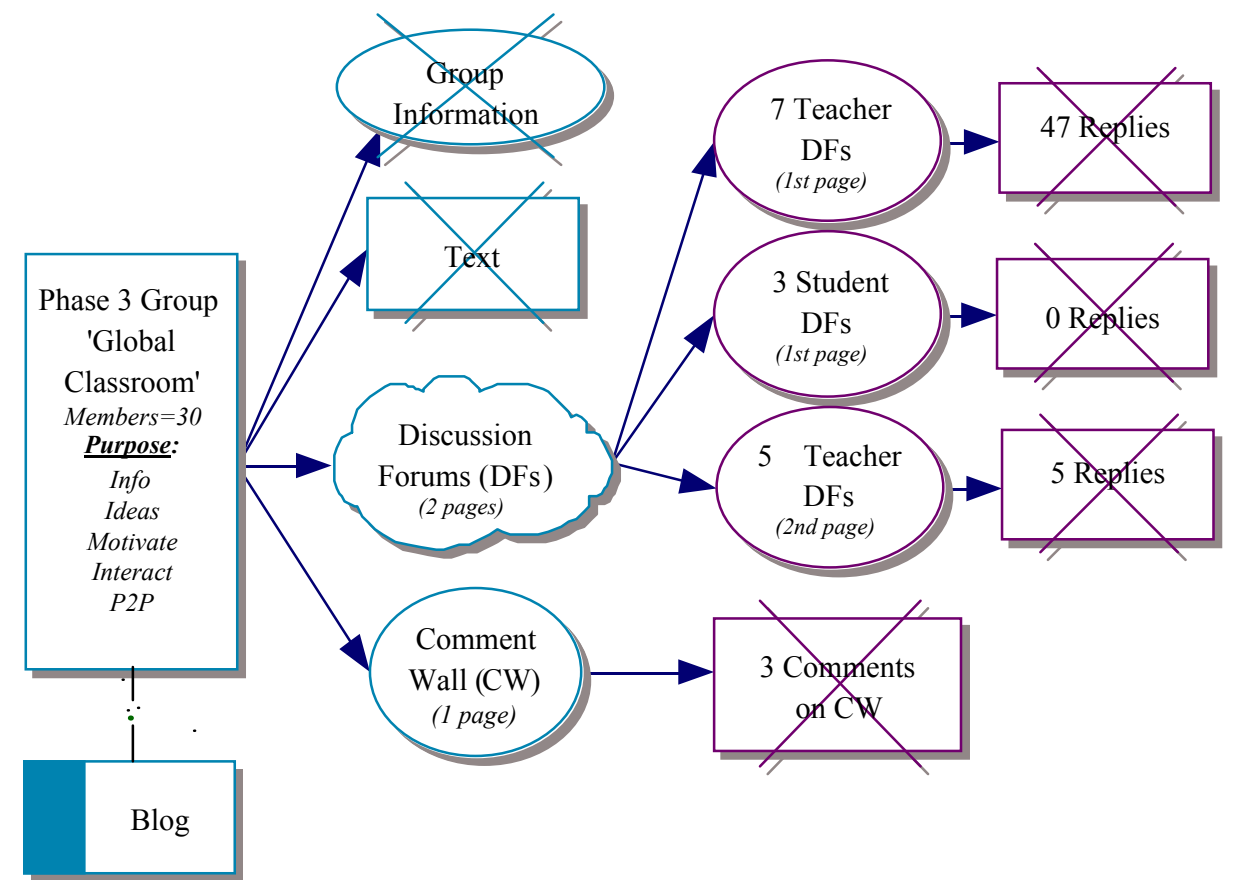

Figure 22: A structured diagram showing the breakdown for the 'Global Classroom' group. This was a first group created to house content for the Global Classroom project.

In the group called 'StudentGroups', teams of students created discussion forums to share ideas and post content, using the 'Replies' area of the Discussion Forum for their team. The number of discussion forums did fit on one page and remained manageable.

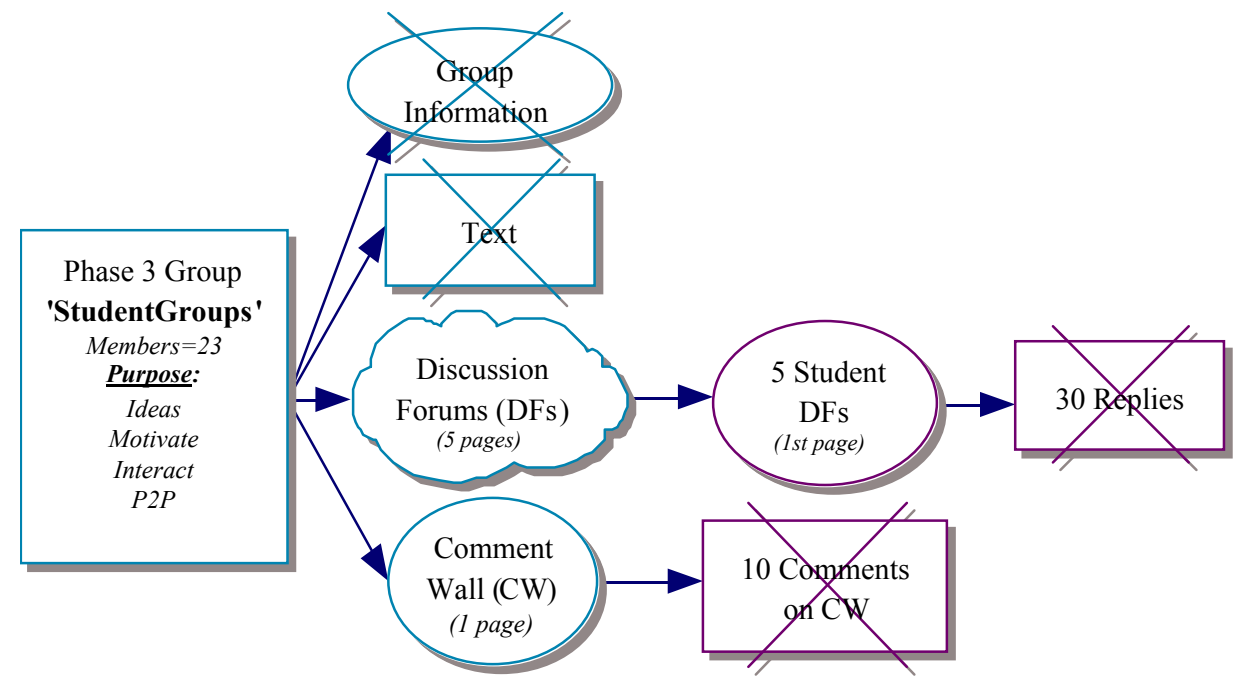

Figure 23: A structured diagram showing the breakdown for the 'StudentGroups' group. This was a second group created to house content for the Global Classroom project.

\section{Findings when Designing for Student-Centred Learning}

- I found that the text box provided a good information retrieval mechanism for students to obtain instructions, links and media.

- Discussion groups were excellent places for interaction within a topic, but having more than ten discussion forums in a group (more than one page of these) caused issues due to 
the difficulty in managing the number of student interactions and in finding content. (It was not possible to automatically set the maximum number of Discussion Forums to ten.)

- Groups were helpful in gaining an overview of the student's interests and broader activity.

Using blogs rather than discussion forums for students to publish their work was beneficial in numerous ways. Four of the most significant of these are listed below.

- Although assessment occurred throughout the semester, using blogs greatly assisted the teacher at the end of the semester to view the student's progress of content, interaction and communication.

- The blog comments were usually easily accessible and, hence more manageable.

- Students could at any time click on their own 'Blog Posts' from their 'My Page' to view all of their work and feedback. They could also view any other member's blog from that member's 'My Page'.

\section{Conclusion}

Initially, I did not consider that analysing each of the online spaces within the social media site in such detail would be such a key foci for this study. The dynamic nature of the site and its ability to encourage new ways of interactivity forced this structural thinking and analysis. The quick access links, such as those on the main menu and the main page, were vital in channelling the student interaction quickly into the desired pathways. The effective search mechanism was also very useful in finding members and student content. The design structure of teacher projects changed, depending on the project aims, but an efficient and effective structure was important to ensure that student feedback and interaction did not become congested and that students did not become distracted or overloaded with information. Through this research study, a learning framework that valued the unique attributes of social media evolved. The action research cycle, including the process of dissecting each of the online spaces, as discussed in this article, was a core component in the study.

Like Luckin et al. (2009), I found that the use of the online spaces and tools were complex. The manner in which social and participatory media were used in the learning design of this study draws on the new sciences of chaos and complexity to develop a different sense of instruction, as explained by Doll (2012). He describes this new type of instruction as open, dynamic, relational, creative, and systems oriented. In this study, the teacher projects were only one of the many avenues of learning that were created in the social software framework. Opportunities to provide learners with a more individualised learning space than the face-to-face classroom were achieved though the student 'My Page', individual blogs, and student directed groups. Students were able to obtain personalised feedback (from peers and teacher) and could create their own groups and discussion forums to share and build knowledge based on their interests. Students could also learn and interact with those from different subjects and age levels as well as with schools internationally. Through the interactivity and the open publishing nature of the social software, students were able to be models for their peers.

It is now common for many learning management systems to offer a range of social spaces such as blogs, groups, and discussion forums. This article focused on building a student-centred learning environment and provided a discussion on the issues, choices, and complexity when designing learning with such spaces. Thomas and Brown (2011) point out that these environments are enabling our students to learn in new ways, sometimes called "hanging out", "messing around" and "geeking out". But, as I found, hidden in the shadows of these new ways are the quick access links and pathways that enable efficient and effective interaction and information flow. 


\section{References}

Armstrong, F., \& Moore, M. (2004). Action research: Developing inclusive practice and transforming cultures. In F. Armstrong \& M. Moore (Eds.), Action research for inclusive education: Changing places, changing practice, changing minds (pp. 1-16). London; New York: RoutledgeFalmer.

Blatchford, P., Kutnick, P., Baines, E., \& Galton, M. (2003). Towards a social pedagogy of classroom group work. International Journal of Educational Research, 39, 153-172.

Bouchard, P. (2011). Network promises and their implications. Revista de Universidady Sociedad del Conocimiento (RUSC), 8(1), 288-302. Retrieved from http://rusc.uoc.edu/ojs/index.php/rusc/article/viewFile/v8n1-bouchard/v8n1-bouchard-eng

Boyd, D., \& Ellison, N. (2007). Social network sites: Definition, history and scholarship. Journal of Computer-Mediated Communication, 13(1), 210-230.

Casey, G. (2011). Knowledge-building: Designing for learning using social and participatory media. eLearning Papers, 27, 1-7. Retrieved from http://elearningeuropa.info/en/node/111104?paper=111465

Casey, G., \& Evans, T. (2011). Designing for learning: Online social networks as a classroom environment. The International Review of Research in Open and Distance Learning, 12(7), 1-26. Retrieved from http://www.irrodl.org/index.php/irrodl/article/view/1011

Conole, G., Gallery, R., \& Culver, J. (2011). Frameworks for understanding the nature of interactions, networking, and community in a social networking site for academic practice. International Review of Research in Open and Distance Learning, 119-138.

Davidson, C., \& Goldberg, D. (2009). The future of learning institutions in a digital age. Massachusetts Institute of Technology.

Davis, B., \& Sumara, D. (2006). Complexity and education: Inquiries into learning, teaching, and research. Mahwah, N.J: Lawrence Erlbaum Associates.

Davis, B., \& Sumara, D. (2012). Fitting teacher education in/to/for an increasingly complex world. Complicity: An International Journal of Complexity and Education, 9(1), 30-34.

Doll, W. E. (2005). Chaos and complexity theories. In W. E. Doll, M. J. Fleener, \& J. St. Julien (Eds.), Chaos, complexity, curriculum and culture: A conversation. New York: P. Lang.

Doll, W. E. (2012). Complexity and the culture of curriculum. Complicity: An International Journal of Complexity and Education, 9(1), 10-29.

Hansen, D., Shneidermann, B., \& Smith, M. (2009). Analyzing social media networks: Learning by doing with Node XL Available from http://casci.umd.edu/NodeXL_Teaching

Hayles, N. K. (1990). Chaos bound: Orderly disorder in contemporary literature and science. Ithaca, N.Y: Cornell University Press.

Hayles, N. K. (1991). Chaos and order: Complex dynamics in literature and science. Chicago and London: The University of Chicago Press.

Jones, C. (2010). Editorial. A new generation of learners? The net generation and digital natives. Learning, Media and Technology, 35(4), 365-368.

Luckin, R., Clark, W., Graber, R., Logan, K., Mee, A., \& Loliver, M. (2009). Do Web 2.0 tools really open the doors to learning? Practices, perceptions and profiles of 11-16-year-old students. Learning, Media and Technology, 34(2), 87-104.

Markham, A. (2013). The dramaturgy of digital experience. Retrieved from http://www.markham.internetinquiry.org/writing/dramaturgyprepubdraft.pdf

Merchant, G. (2011). Unravelling the social network: Theory and research. Learning Media and Technology, 37(1), 4-19. 
Nuthall, G. (2007). The hidden lives of learners. Wellington, N.Z: New Zealand Council for Educational Research.

Ravenscroft, A., \& Cook, J. (2007). New horizons in learning design. In H. Beetham \& R. Sharpe (Eds.), Rethinking pedagogy for a digital age (pp. 207-218). New York Routledge.

Ryan, S., Magro, M., \& Sharp, J. (2011). Exploring educational and cultural adaption through social networking sites. Journal of Information Technolgy Education: Innovations in Practice, 10, 1-16. Retrieved from http://www.jite.org/documents/Vol10/JITEv10IIPp001-016Ryan883.pdf

Selwyn, N. (2008). From state-of-the-art to state-of-the-actural? Introduction to a special issue. Technology, Pedagogy and Education, 17(2), 83-87.

Selwyn, N., \& Grant, L. (2009). Researching the realities of social software use - An introduction. Learning Media and Technology, 34(2), 79-86.

Siemens, G. (2008). Learning and knowing in networks: Changing roles for educators and designers. Paper 105: University of Georgia IT Forum. Retrieved from http://it.coe.uga.edu/itforum/Paper105/Siemens.pdf

Sumara, D., \& Davis, B. (2009). Complexity theory and action research. In S. Nofftke \& B. Somekh (Eds.), The Sage handbook of educational action research (pp. 358-369). London: Sage.

Thomas, D., \& Brown, J., S. (2011). A new culture of learning : Cultivating the imagination for a world of constant change. Charleston, USA: Amazon.com. 


\section{Appendix 1 - Research Tags}

Each of the research questions represent a research theme and each theme (Teacher, Student, and Learning - shown earlier in Figure 1) was broken down into categories. Each category was allocated a Tag.

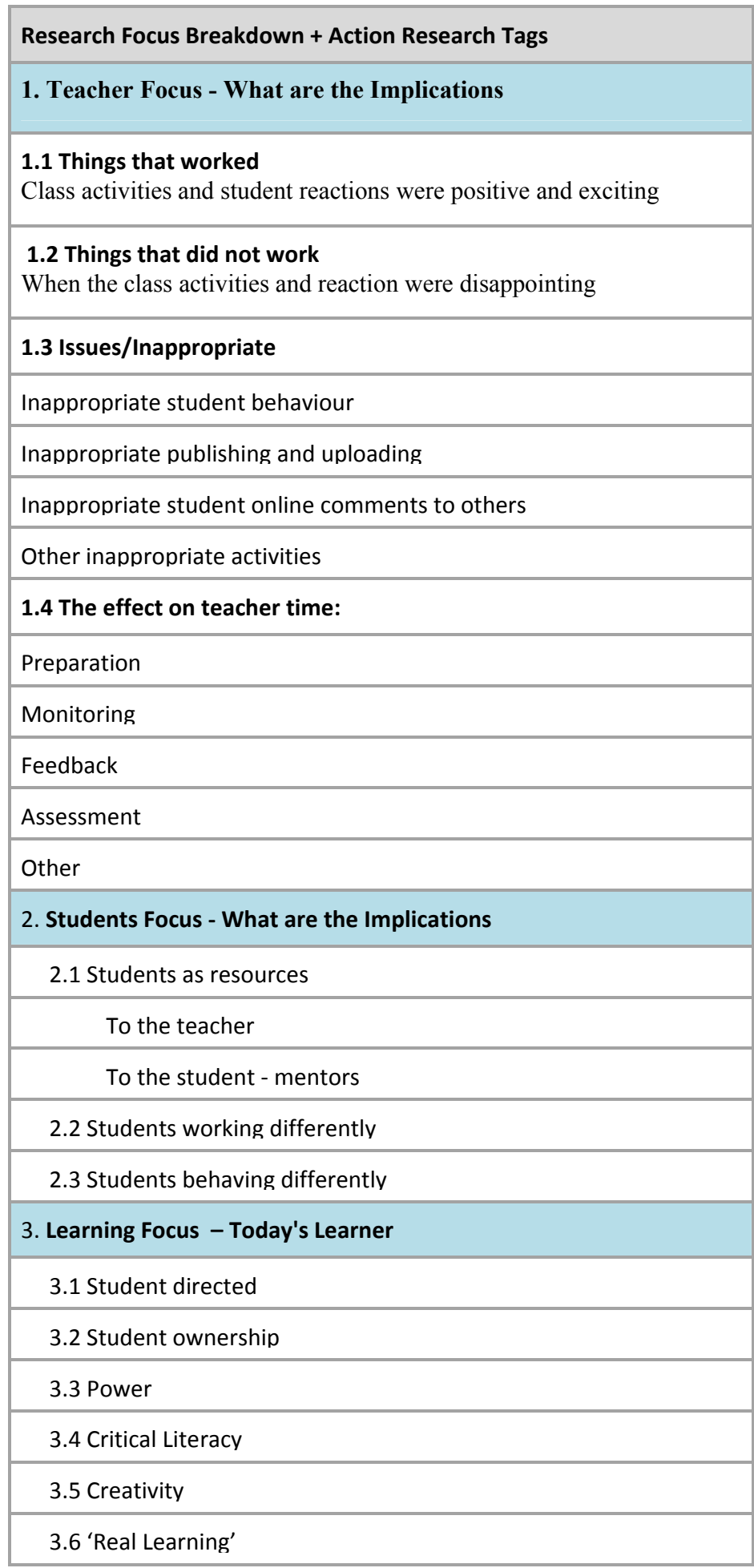




\section{Appendix 2 - Phase 2: Data Breakdown}

Screen clips from the student online activity was tagged over the eighteen-months of data collection. This data was summarised using a dot-point format for each phase. Some examples are shown below.

\section{Teacher - What are the Implications?}

\subsection{Things that worked}

- Online projects MashUps, Data Visualisation, Google Earth, Get Creative etc

- Greater flexibility for students to choose their own avatar and name

- Student \& teacher made help tutorials

- Emails and comments to students to adjust their behaviour rather than suspending

- Tips \& Tricks help groups

- Published teacher project list of 'To Do'

- Peer feedback

- Using Ning groups to post project information

- Making real world connections to skills, concepts and applications

- Teacher needs to be a model for students

- Students make good models for each other - both good and bad models

- Providing scaffolding helped students understand teacher expectations

\subsection{Things that did not work}

- Time for math students to upload their own videos

- Student access to Youtube, Vimeo, Teacher Tube

\subsection{Issues/Inappropriate}

- Experimentation

- Lack of understanding

- Violence in animations

- A few students still continue to attempt to upload inappropriate pics

\section{Students - What are the Implications?}

\subsection{Students as resources for the teacher.}

- Student research helps inform the teacher

- Pivot

- Students wanting you to be part of the new learning they can offer the class

- Student videos can also teach the teacher

- Students can be encouraged to produce help videos that others need

- Students helping with assessment

\subsection{Students as resources for their peers.}

- Student made help videos tutorials

- Humour, support \& encouragement

- Constructive peer feedback

\subsection{Students working differently}

- Using students as part of their learning support structure

- Students exploring websites as part of their knowledge building focus then sharing these - peers can also benefit from what they have found.

- Out of school Ning activity

- Peers and teacher giving 'Gifts' \& 'Likes'

- Students using pseudonyms with flexible names

- Students having their own space, 'My Page', with student created profiles

- Students publishing their work including use of blogs \& discussion forums

- Students having the flexibility to leave comments for any member of the Ning and the ability to join any Ning group 


\section{Acknowledgement}

I would like to acknowledge my doctorial supervisors Professor Terry Evans and Dr Muriel Wells, Deakin University, Australia, for their continued advice and support throughout this doctoral research study.

\section{Biography}

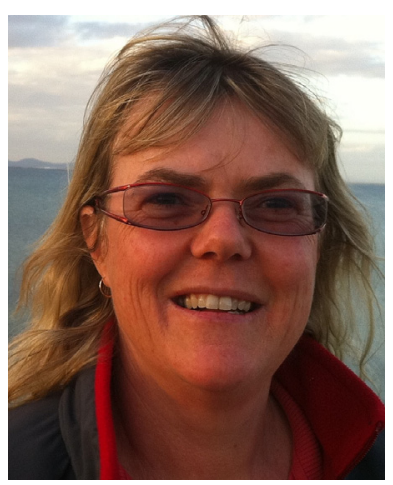

As this article was finalised, Gail Casey was in the examination phase of her doctorate of education through Deakin University, Australia. Her doctoral research has now been published in five peer reviewed journals. In 2012, Gail presented at two peer reviewed conferences in the USA (EdMedia, Denver and ISTE, San Diego) and was awarded, by ISTE, first place in the SIGOL Online Learning Awards for the innovative contribution her research has made. She is a currently writing as part of a publication scholarship and is in search of a postdoctoral research position to further her work on how educators may take advantage of the unique qualities of social and participatory media. Her work can be found at http://gcasey.wikispaces.com/Presentations 